\title{
THE PARTICIPATION OF SMALL MUSEUMS IN VISITOR RESEARCH
}

BY

CASIMAR LARKIN

A dissertation submitted to the Victoria University of Wellington

in partial fulfilment of the requirements for the degree of

Master of Museum \& Heritage Studies

Victoria University of Wellington

2011 


\begin{abstract}
Visitor research appears to be a practice which currently has limited application in New Zealand, especially within small museums. There are challenges in undertaking such research, which have led to an emphasis placed upon collecting visitation numbers. Visitor research is a practice which can be used by museums for a range of purposes, such as improving exhibitions, future planning, or for funding bids. In this way, promoting a range of visitor research methods can enhance the overall value of data gathered.
\end{abstract}

Using Museums Aotearoa's National Visitor Survey as a starting point, this research explores the needs of small museums with regard to visitor research, and also looks into the ways in which these needs might be met. Seven face-to-face interviews were conducted with key people in small museums and galleries. Diversity within the research sample ensured opportunities for comparison, building a picture of differences and similarities in their perceptions of visitor research. The interview responses generated themes around current and ideal practice, funding and management, and community value and involvement.

Many reasons emerged as to why small museums and galleries do not carry out visitor research. Shortages of money and staff were two of the main barriers identified. These and other limitations, such as a lack of experience with implementation and analysis, need to be addressed before an institution can seriously undertake valuable visitor research. The findings suggest that within this group of small museums and galleries there is generally a limited understanding about visitor research and the usefulness of the collected data, often restricting practice. There are a number of benefits which would result from access to experts to educate and support visitor research practice. However, there is also the need for funding, possibly in the form of "start up" grants. If more visitor research was undertaken using such support mechanisms, it could ultimately improve the operation of small museums, by creating benchmarks for reporting and potentially increasing funding. 


\section{Acknowledgements}

This research would not have been possible without the support and guidance of my academic supervisors. I owe my deepest gratitude to Dr. Lee Davidson from the Museum \& Heritage Studies Department of Victoria University of Wellington, and Lisa McCauley (general visitor research whiz, formerly of the Auckland War Memorial Museum's Visitor Market Research team). You have both helped me immensely in completing something remarkable; something I never thought would have been possible a year ago. I would also like to thank Dr. Conal McCarthy, Programme Director of the Museum \& Heritage Studies Department, for keeping me on my toes museologically over the last two years.

It is also a pleasure to thank those who made this research possible through their support as friends and family (and proof-readers). Thank you to Morgan Bennet for putting up with my extremes in temper throughout this process, getting me to the end of a long year in one piece, and for your proof-reading and editing skills. Thanks also to Melanie and Stuart McBain, and Frances Le Vaillant for your willingness to help with proofreading and your constant words of support and praise. I also want to thank my father, Laurence Larkin, for making sure I have grown up knowing I can achieve whatever I choose to.

I am indebted to my fellow students and colleagues who have also supported me. To Naiomi Murgatroyd, Emily Murray, and David Luoni for always being there to talk (or complain) to when I needed, also going through the highs and the lows. To Jaqui Knowles for providing advice and always being enthusiastic about my research, and to Waimātao Familton for ensuring I had the time off work to get this research finished.

Finally, I would also like to show my gratitude to the people who agreed to be interviewed. Without your generosity this would not have been possible. You have been integral in this process and I hope your honesty and passion shines through and can help to inspire other museums. 


\section{Table of Contents}

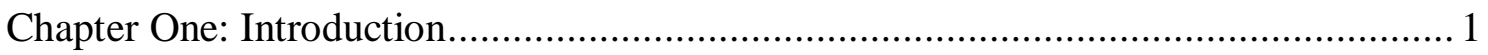

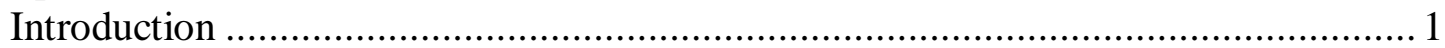

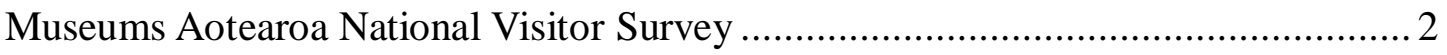

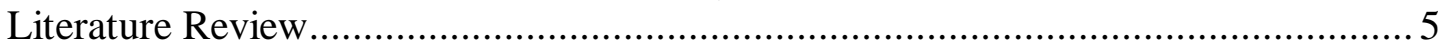

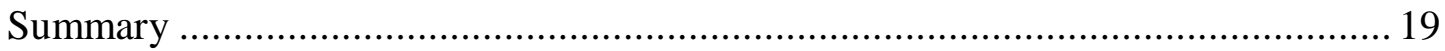

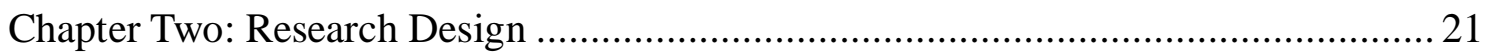

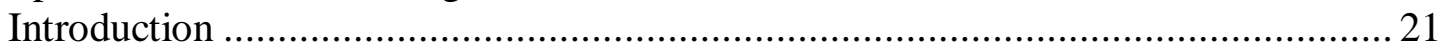

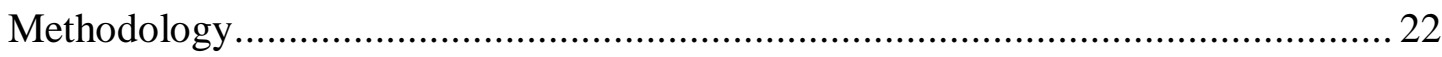

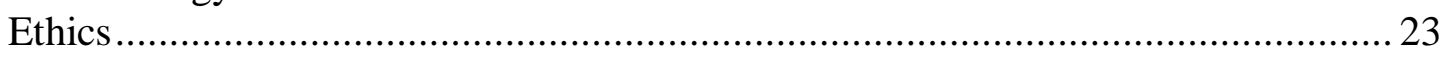

The Research Population and the Sample ........................................................ 25

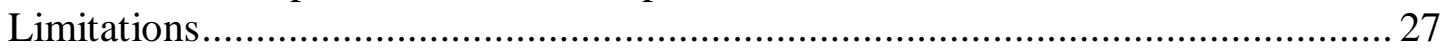

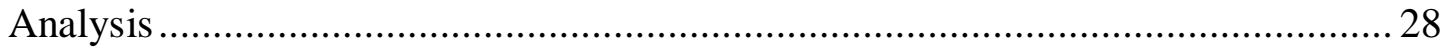

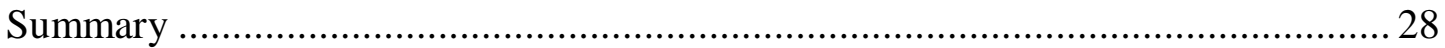

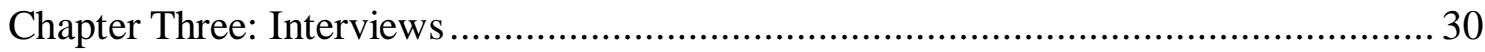

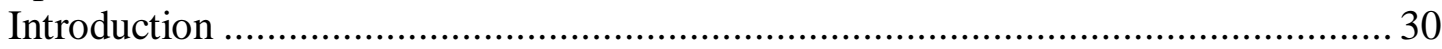

Interview 1: Urban Art Gallery.................................................................... 30

Interview 2: Urban Heritage Building/Museum .................................................. 32

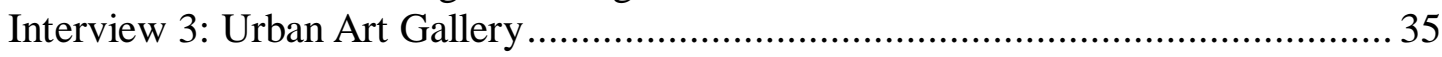

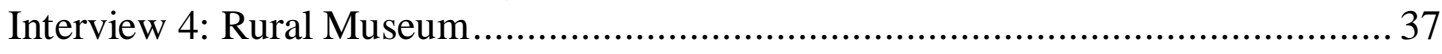

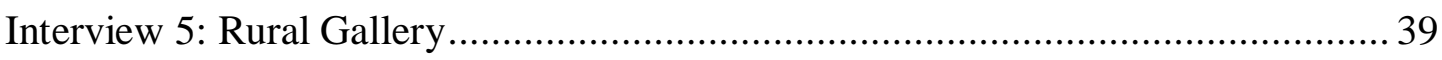

Interview 6: Medium Urban Museum.................................................................. 41

Interview 7: Medium Urban Historic Building/Museum...................................... 43

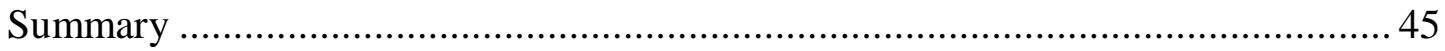

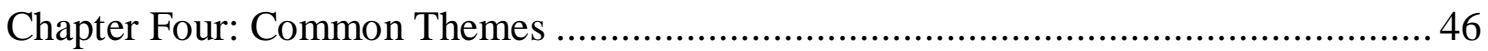

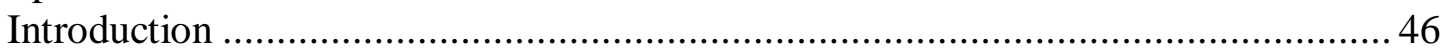

Current Visitor Research Practice ................................................................... 46

Perceived Benefits of Visitor Research......................................................... 47

Barriers to Visitor Research................................................................................. 49

Expanding the Understanding of Visitor Research............................................ 51

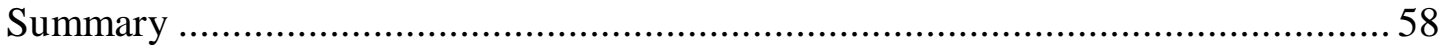

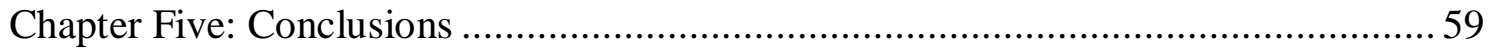

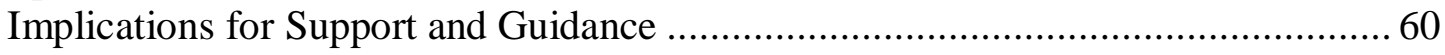

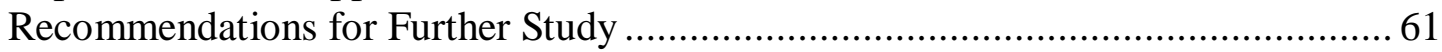

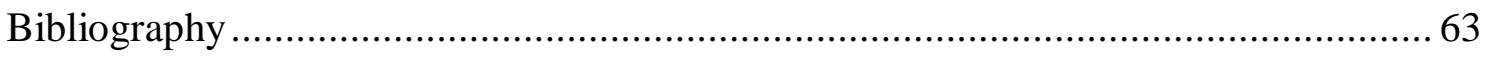

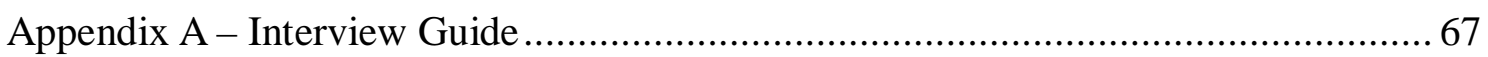

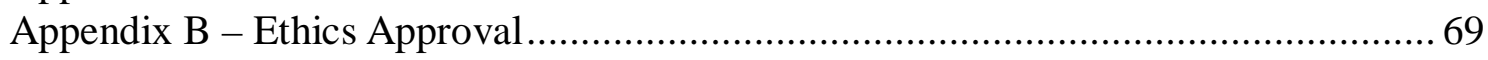

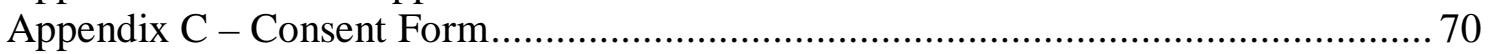

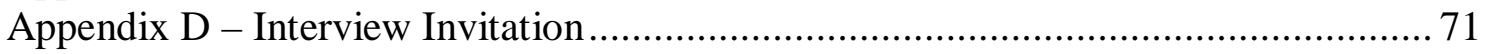




\section{Chapter One: Introduction}

\section{Introduction}

Historically, research into the group dynamics and perspectives of all museum visitors has been neglected. As McLean notes, museum exhibitions have traditionally been oneway conversations, where museums do the talking and visitors the listening. ${ }^{1}$ However, theorists such as Hooper-Greenhill argue that the last twenty years or so have seen the field of visitor research develop, with visitors more frequently becoming accepted as active interpreters and meaning-makers of museums and cultural sites. ${ }^{2}$ HooperGreenhill further explains this evolution as based upon the realisation that there are "vital philosophical questions about the place and purpose of museums which can only be answered if and when museums broaden their perspectives to include the views of their audiences”. ${ }^{3}$ Despite the progress of visitor research within museums, the proposition that the interests and needs of their visitors should be considered can still be met with resistance; the creators of exhibitions often disregard public interest by assuming these interests are the same, or irrelevant and out of line with their own. Kotler insists that with a bit of investigation, common ground can be found which would provide more relevant experiences for visitors, while retaining the creators' desired levels of intellectual depth. ${ }^{4}$

The research I have undertaken is based upon investigating the needs of small museums with regard to visitor research, as well as exploring ways in which these needs might be met. Throughout Chapter One, I will outline the reasons why I chose to undertake my research within the field of visitor research and why I believe it is especially important that small museums receive assistance in this area. My interest in this field was initially roused during participation in Museums Aotearoa's National Visitor Survey (MANVS) which is explained in the next section. From this point I reviewed the theoretical literature surrounding visitor research, starting with the history of museums and leisure

1 Kathleen McLean, “Museum Exhibitions and the Dynamics of Dialogue,” Daedalus 128 (1999): 89.

2 Eilean Hooper-Greenhill, "Studying Visitors,” in A Companion to Museum Studies, ed. Sharon Macdonald, Blackwell Companions in Cultural Studies 12 (Malden, MA: Blackwell Pub, 2006), 362.

3 Hooper-Greenhill, 2006, 362.

4 Neil Kotler, "Delivering Experience: Marketing the Museum’s Full Range of Assets,” Museum News, May/June 1999, accessed May 22, 2010, http://www.aam-us.org/pubs/mn/MN_MJ99_DeliveringExperience.cfm?. 
and how visitor research fits within this history. This context helped to inform the exploration of museums and their communities, as well as visitor experience, which in turn led to the examination of how a favourable balance can be reached between museums' goals and visitors' needs . These considerations are applied to the practice of visitor research, discussed below, especially lacking in small museums with less research experience and fewer resources.

I make the case throughout this chapter that visitor research needs to be carried out to allow museums to interpret who their visitors are, what they want from museums, whether the museum is meeting their visitors' needs and expectations, and assessing the extent to which learning outcomes are achieved. Visitors can inform museums on the best way to engage the visiting public, by indicating what they would like to see of themselves in the displays in order to make vital personal connections. The visitors' positive experiences will in turn help to justify a museum’s value as a civic institution.

\section{Museums Aotearoa National Visitor Survey}

Over the summer of 2009/2010 I worked on the administration of a visitor research pilot study which was undertaken by Museums Aotearoa and Victoria University of Wellington (VUW). Museums Aotearoa is a professional organisation whose mission is "to raise the profile, strengthen the performance, and increase the value of museums and galleries to their stakeholders and the community". ${ }^{5}$ Museum sector research is one of their current priorities, with one of the goals of this project being the establishment of a national framework which would standardise visitor profile research across New Zealand's museums and galleries. In November 2009 an email-based scoping survey was initiated and sent to all Museums Aotearoa's members to ascertain the broader sector's level of interest and enthusiasm for the idea of MANVS and subsequent database. Overall, a positive response was received from the participating museums.

5 “Museums Aotearoa: About Us.” Museums Aotearoa, accessed March 11, 2011, http://www.museumsaotearoa.org.nz/Site/about/default.aspx. 


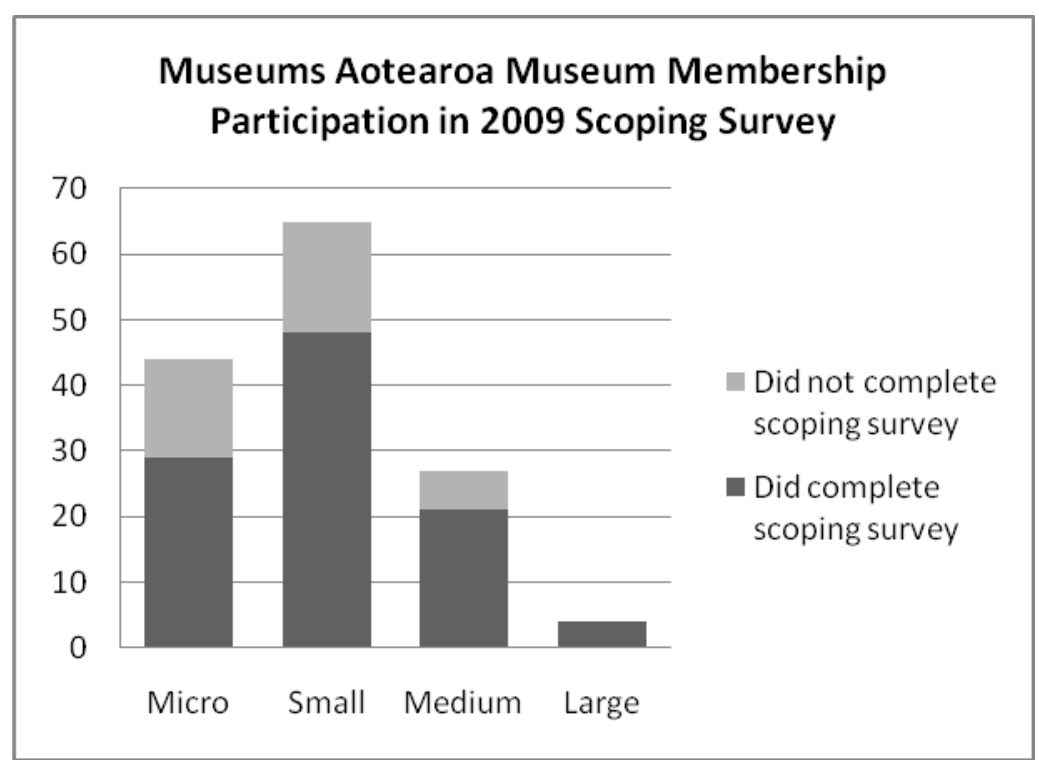

Figure1: Museums Aotearoa’s Membership Participation in 2009 Scoping Survey

There was a significant 74\% completion rate for the scoping survey. Figure 1 shows a remarkably even spread between the micro, small and medium museums, which combined have an average of $72 \%$ for their completion rate. Over $80 \%$ of respondents were either extremely or very supportive of the idea of having a standardised visitor survey conducted annually by museums across the country.

My involvement included working with a sample of the micro, small and medium museums to conduct a pilot of a standardised visitor survey. This was the first step in building a nationwide database of museum visitor profile research. A cross-section of museums and galleries from around New Zealand were therefore approached to assist with the piloting of MANVS. The museums chosen were based on the initial scoping survey results, with a selection that had responded favourably invited to be a part of the pilot study in February and March 2010. Twelve museums and galleries, of various sizes and from across the country, accepted this invitation. In this context size was defined by using the number of Full-Time Equivalent (FTE) staff employed by the museums, as this is the criterion Museums Aotearoa use (refer to Table 1, page 4). As is discussed later, there are different ways size can be defined. 


\begin{tabular}{|l|l|}
\hline Micro & 0 FTE staff \\
\hline Small & 1-5 FTE staff \\
\hline Medium & 6-20 FTE staff \\
\hline Large & 21+ FTE staff \\
\hline
\end{tabular}

Table 1: Museums Aotearoa’s definition of museum size.

Each museum was asked to survey their visitors for one week, using one of two methods to complete the surveys. The first option offered was an intervieweradministered survey. This was explained as an ideal method for achieving good response rates from a range of visitors, but required the availability of an interviewer. The second option was the self-administered survey, to be offered either actively ${ }^{6}$ or passively $^{7}$ and filled in by the visitors. It was noted that this option would be less timeintensive for museums with staffing restrictions, but is generally not as reliable for capturing a representative sample of a museum's visitors. The museums were also provided with full instructions for sampling, delivery and data recording. The decision of which option to use was up to the individual institutions, dependant on their available resources.

I used this project as a starting point for my research due to the observation that the micro and small museums (hereafter referred to collectively as 'small museums') participating in MANVS were more likely to choose the self-complete option. This choice resulted in limited numbers of surveys being completed (one museum collected six over the full week) reducing the impact of the collected data. I decided to use the data provided by the scoping survey to look into past visitor research conducted by small museums to compare with medium and large ones. At first I discovered the majority of museums that completed the scoping survey stated they carried out visitor research regularly. However, further analysis showed this research to be mainly composed of visitation numbers and the information provided by visitor books. It was only the large museums that were regularly using face-to-face and self-complete exit

6 Each visitor is handed a survey and invited to complete and return it at the end of their visit.

7 A box of surveys is left in an obvious place (for example an entry or exit point) with a sign inviting visitors to 'please take one'. 
surveys (amongst other types of visitor research), which are the methods being developed for MANVS. This indicated very few museums in New Zealand are undertaking a range of visitor research regularly, but emphasised the fact that the small museums in particular are undertaking the least. These findings outline current visitor research practice in New Zealand. They suggest that despite its importance, visitor research is still frequently seen as a luxury, or is an underrated or misunderstood practice within the museum industry.

\section{Literature Review}

\section{Introduction}

As the field of visitor research has gradually developed within the international museum sector, a small number of leading theorists have emerged to help inform better practice, who are discussed further below. This group includes researchers such as HooperGreenhill, who writes about the shifts in museological thinking and sees visitor research as "a rapidly evolving, controversial, and dynamic field". ${ }^{8}$ There is also McLean who discusses the importance of exhibitions and the "intentions of the presenter and the experience of the spectator". ${ }^{9}$ Kotler, as a market researcher, bases his work on international case studies and is more concerned with using visitor research as a tool in the marketing of museums. Meanwhile, theorists Falk, Dierking and Hood have used visitor research to formulate experience models ${ }^{10}$ and theories surrounding visitation and non-visitation. ${ }^{11}$ Other theorists, such as Lynch et al. are concerned with how "the concept of leisure changes over time and across cultures”, as well as what people want with regard to their leisure options and the implications of this for museum visiting. ${ }^{12}$ Scott acknowledges the need for a new and more sophisticated method to provide evidence of the value museums have in their communities. ${ }^{13}$

8 Hooper-Greenhill, 2006, 362.

9 McLean, 1999, 83.

10 John H Falk and Lynn D Dierking, The Museum Experience (Washington, D.C: Whalesback Books, 1992).

11 Marilyn G. Hood, “Staying Away: Why People Choose Not to Visit Museums,” in Reinventing the Museum: Historical and Contemporary Perspectives on the Paradigm Shift, ed. Gail Anderson (Walnut Creek, California: AltaMira Press, 2004), 402.

12 Rob Lynch et al., Leisure and Change: Implications for Museums in the 21st Century (Sydney: University of Technology Sydney; Powerhouse Museum, 2000), 1.

13 Carol A. Scott, "Exploring the Evidence Base for Museum Value," Museum Management and Curatorship 24 (2009): 195-212. 
Reflecting on the type of literature available surrounding visitor research and small museums, the following chapter has been divided into two distinct sections. The first section examines the theoretical literature surrounding visitor research: including the changing face of museums and leisure, the development of museum visitor research, museums and their communities, visitor motivations and experiences, and museums' goals and visitors' needs. The second section focuses specifically on small museums and visitor research, exploring the practical guidance and resources available for museums who are interested in undertaking visitor research. In this way, the research and theory can be seen to be linked to practice, designed to improve museums by assisting with visitor research through the different stages.

\section{The Changing Face of Museums and Leisure}

Historically, museums were powerful public civilisers. They were didactic institutions, reluctant to listen to visitors’ opinions, and using what Hooper-Greenhill calls an “expert-to-novice model of communication”. ${ }^{14}$ This one-sidedness was considered vital, as in the eighteenth and nineteenth centuries museums had the important job of morally improving the lower classes of society. Neal argues that even up to the late 1980s many museums had not progressed in their exhibit evolution, and were still "frozen in the suspended animation of display techniques that developed in the late 1700s". ${ }^{15}$

However, museums' functions in society are continually changing, they are becoming more inviting civic spaces for people to explore at their own pace.

Alongside this history of museums can be seen the history of leisure, dating back to the fifteenth century. Originally "modernity produced leisure in keeping with the thought of the era: leisure as a realm of self-fulfilment and life satisfaction”. ${ }^{16}$ The impact of postmodernity on leisure is now obvious, with changes emerging from "the current social conditions of a rapidly changing culture [creating] a heightened self-consciousness reflected in contemporary leisure". ${ }^{17}$ In recent times, an expectation of rapid change, fragmentation and flexibility has developed, leading to fewer museum visits. Lynch et al. argue this reflects "a declining investment in time ... and depth of involvement in

14 Hooper-Greenhill, 2006, 362.

15 Arminta Neal, Help for the Small Museum: Handbook of Exhibit Ideas and Methods (Boulder, Colorado: Pruett Publishing Company, 1987), 2.

16 Lynch et al., 2000, 4.

17 Lynch et al., 2000, 5. 
some activities”. ${ }^{18}$ Museums must now compete in the leisure marketplace alongside a variety of attractions, including theatres, shopping malls and fun parks, as well as homebased activities such as computer games. It follows that museums must consider how people view their own leisure time in order to formulate ways to appear more appealing to the general public.

Despite the necessity for museums to compete in the leisure industry, Doering maintains they are reluctant to accept the implications of being a leisure-time activity. She suggests that museums do not recognise they are only a small part in a full range of activities available to serve people's needs for "personal self-definitions and agendas for development”. ${ }^{19}$ Doering adds that if museums were to acknowledge their place in the leisure market, it follows they would also have to admit their role as "service" institutions, perhaps more similar to libraries. $^{20}$

\section{The Development of Museum Visitor Research}

According to Hooper-Greenhill, surveying visitors for the purpose of exhibition evaluation and collecting their demographic details started to be practised in museums from the 1960s. ${ }^{21}$ She has described the progress made by museums in the field of visitor research as the result of "several, loosely interlocking intellectual journeys", with the majority of this progress happening since the $1980 \mathrm{~s}^{22}$ Prior to this time there was a focus on observing visitors' behaviour while they explored the museum, as this was considered the most objective and reliable way of gathering feedback to improve exhibition design. ${ }^{23}$ Hooper-Greenhill stresses the importance of developing different types of visitor research, such as visitor profile studies and exhibition evaluation. She states that for any museum "basic knowledge of visiting patterns and the breakdown of types of user ... is regarded as essential management information”. ${ }^{24}$

While past quantitative studies collated basic demographic information, which was useful in providing informative overviews of the social use of museums, one limitation

18 Lynch et al., 2000, 9.

19 Zahava D. Doering, "Strangers, Guests, or Clients? Visitor Experiences in Museums," in Museum Management and Marketing, eds. Richard Sandell and Robert R. Janes (Routledge, 2007), 335.

20 Doering, 2007, 335.

21 Hooper-Greenhill, 2006, 364.

22 Hooper-Greenhill, 2006, 362-363.

23 Hooper-Greenhill, 2006, 363.

${ }^{24}$ Hooper-Greenhill, 2006, 368. 
was that this information could not reveal why people did not visit museums. ${ }^{25}$ HooperGreenhill further states how past general visitor research shows “audiences [are] less malleable and less predictable than was at first thought” and visitors all "have an agenda of their own”. ${ }^{26}$ Therefore, the meaning people take away from their museum experience varies vastly depending on many different aspects of their lives. These factors can include, but are not limited to, social status, educational background, gender and ethnicity. Hooper-Greenhill believes that recognising the impact of these factors is vital and can lead museums to create exhibitions and events which deliver more meaning to visitors. ${ }^{27}$ For many museums, it is necessary to update their assumptions about visitors and the reasons that they visit.

Large amounts of money have become involved in the expansion and promotion of the leisure industry internationally, leading to an expectation by many people of exciting, dramatic and memorable experiences from their leisure choices. However, this is often for charged leisure experiences, rather than for museums which are usually free and locally funded. Due to operational costs, museums have less money to spend on creating experiences which can compete in this leisure industry. Kotler's research expands on this by stating that small and medium-sized museums are often "lacking treasured artefacts and icons, [and therefore] face the challenge of creating compelling stories”. ${ }^{28}$ To maximise the interest and appeal of museums' stories, there is the need for quality research to be undertaken and appropriately aimed at current and potential visitors.

Museums have therefore become vulnerable due to a lack of funding being available for them. Some have also failed to build strong community ties, leading to fewer connections with their visitors' expectations. ${ }^{29}$ Kotler believes by operating alongside the myriad of other leisure marketplace competitors, museum officials are justifiably seeking more efficient ways to provide consumer value. ${ }^{30}$ It follows that a museum's distinctive offerings need to be uncovered and promoted to establish a recognisable position in this marketplace in order to provide competitive advantages. ${ }^{31}$ Museums are no longer the stand-alone, authoritative institutions they started out as. They are

\footnotetext{
Hooper-Greenhill, 2006, 364-365.

Hooper-Greenhill, 2006, 367.

Hooper-Greenhill, 2006, 372-373.

Kotler, 2001, 419.

Kotler, 2001, 423.

Kotler, 1999, 1.

Kotler, 1999, 3.
} 
becoming increasingly immersed in the competitive leisure industry, forging vital connections with local communities and tourism. In Kotler's opinion, visitor research is important for museums that aim to build a broader audience, as they can focus on the outcomes of their activities, which will reinforce their accountability. ${ }^{32}$

Despite the various attempts at visitor research which many museums have undertaken, Scott argues that the museum industry has been hindered by its failure to pinpoint and articulate its value. ${ }^{33}$ Whitehead supports this, noting that pressing economic issues have led to a requirement that museums justify their existence in order to receive funding. ${ }^{34}$ Scott believes this pressure is due to a decline in all types of funding, coupled with an increasingly challenging economic climate, leading to a greater importance being placed on proving value. ${ }^{35}$

Scott further argues that through the competition emerging throughout the leisure industry, it is now the concept of value which is becoming an "overarching framework with which to articulate, advocate and substantiate the importance of museums in the $21^{\text {st }}$ Century”. ${ }^{36}$ It is Scott's recommendation that value indicators be used to collect data on an annual basis, to develop baselines and time series data and to identify longterm trends. This regularly gathered information should lead the museum sector to develop the ability to prove long-term value to current and potential stakeholders. ${ }^{37}$

Asserting the value of museums provides some of the most powerful arguments for the favourable impact that museums have on individuals and communities. Scott argues that this value is important, as the usual reason for the creation of a museum is to make a positive and useful difference in the quality of people's lives, initially through the community and then beyond. ${ }^{38}$ Similarly, Museums Aotearoa states that museums must be "a central focus of community life ... and be adaptable to the changing needs of their

32 Kotler, 1999, 5.

33 Scott, 2009, 198.

34 Chris Whitehead, "Visiting with Suspicion: Recent Perspectives on Art and Art Museums,” in Heritage, Museums and Galleries: An Introductory Reader, ed. Gerard Corsane (London: Routledge, 2005), 10.

35 Scott, 2009, 195.

36 Scott, 2009, 195.

37 Scott, 2009, 203-204.

8 Scott, 2009, 207-208. 
audiences". ${ }^{39}$ However, it is the ability to actually prove this value which is of increasing importance. The museum sector must "express its worth from a position of strength and [then] defend that position”. ${ }^{40}$ Without this proof, museums can have no way to justify current or future funding, nor firmly cement themselves as cornerstones of their communities.

\section{Museums and Their Communities}

Museums are traditionally meaning-making systems and as such they must strive to provide meaning and direction for their visitors. Each museum is different, placed within a unique community with particular requirements and demands. ${ }^{41}$ In McNichol's opinion, in order for museums to provide meaning they must have the mechanisms in place to interpret who their visitors are and what their visitors want. This theory asserts that museums and their collections often define and visually represent the meanings and ideas of their distinctive communities. ${ }^{42}$ Attention is drawn to the fact that for museums to adequately interpret and represent these cultural areas, each museum must individually engage with their visitors and community. This engagement ensures museums are functioning as flexible spaces, where all who visit can relate, relax, learn and enjoy.

Neal points out that visitor research allows small museums to exhibit on topics of local interest, as well as providing opportunities for social and intellectual stimulation. It is important that local stories are acknowledged and told in depth. Neal believes people visit these small museums to find out about these stories, "not to see another which may differ only slightly from a collection they have seen the day before in a different locale". ${ }^{43}$

The information gathered from visitor research is also vital in order that museums discover who is visiting and to ensure every visitor has positive experiences. These experiences will hopefully encourage them to return. The small museums do not enjoy the resources, visibility or visitation numbers of the large museums, with problems often

\footnotetext{
39 Museums Aotearoa, A Strategy for the Museum Sector in New Zealand (Wellington, New Zealand: Museums Aotearoa, 2005), 35.

40 Scott, 2009, 207-208.

41 Theresa McNichol, "Creative Marketing Strategies in Small Museums: Up Close and Innovative,” International Journal of Nonprofit and Voluntary Sector Marketing 10 (2005): 246.

42 McNichol, 2005, 240.

43 Neal, 1987, 5.
} 
compounded by location issues. Kotler states that these factors mean general museum visitor statistics often reflect the large, urban institutions, rather than the great majority of museums which are small and medium-sized. ${ }^{44}$ However, Kotler also emphasises that regardless of size, or availability of resources and statistics, all museums can benefit from adopting a consumer focus to satisfy the needs of visitors. For the small museums to do this effectively, they must work towards improving their visibility and communicating value to ther communities. ${ }^{45}$

McNichol's research shows the museums that are more likely to draw in community members as visitors initially, may have more success in turning these visitors into volunteers (although the use of volunteers needs to be weighed up with the logistics of their management). This knowledge, used appropriately, could help to alleviate museums' staffing and funding issues. ${ }^{46}$

To help recognise the value of small museums, McNichol argues that all museums, regardless of their size, have name recognition based on being a museum. Museums are instantly perceived as quality institutions in possession of unique attributes, holding the ““intrinsic’ value of museums as gathering places”. ${ }^{47}$ Consequently, within the broader museum sector, small museums are a collaborative network whose members must continue to illustrate and increase their willingness to co-operate and share information. ${ }^{48}$ Kotler and Kotler believe that small museums are in a perfect position to band together to build public relations, as well as promotional and marketing partnerships with other small museums in their area, forming clusters to create tourism destinations. ${ }^{49}$ This idea is reinforced by Museums Aotearoa; this organisation has outlined that one of their priorities is "to encourage networking between museums, particularly at regional level". ${ }^{50}$ However, Spinazze believes some of "the most visible small museums have become so through collaborations with larger organisations”. ${ }^{51}$

44 Kotler, 1999, 4.

45 Kotler, 1999, 4.

46 McNichol, 2005, 244.

47 McNichol, 2005, 243.

48 McNichol, 2005, 242.

49 Neil G Kotler and Philip Kotler, Museum Marketing and Strategy: Designing Missions, Building Audiences, Generating Revenue and Resources, 2nd ed. (San Francisco, CA: Jossey-Bass, 2008), 26.

50 Museums Aotearoa, 2005, 25.

51 Angela T. Spinazze, “Technology's No Tea Party for Small Museums,” in The Digital Museum: A Think Guide, eds. Herminia Din and Phyllis Hecht (Washington, DC: American Association of Museums, 2007), 129. 
Therefore, it can be argued that it is beneficial for small museums to collaborate with other institutions, regardless of size, helping themselves to stand out and be effectively promoted.

\section{Visitor Motivations and Experiences}

In order to fully utilise data gathered from visitor research it is helpful to understand the variety of motivations people have for visiting museums and how these motivations influence their experiences. An understanding of visitor motivation theories, such as those discussed below, can lead museums to create experiences which provide meaning for a variety of visitors. As visitor research has evolved it has helped to inform and define visitor motivation theories, exploring not only who visits a museum and why, but also who does not visit and why.

When a person visits a museum, Doering defines the experiences they find most satisfying as forming four categories: object experiences, cognitive experiences, introspective experiences, and social experiences. ${ }^{52}$ A museum accountable to visitors for all of these experiences provides enhanced and supportive settings, removing barriers and constraints which interfere or detract from great museum experiences. ${ }^{53}$

While many museums work hard to appeal to a wide range of visitors, there is little control over why an individual actually decides to visit. Hood calls decision-making variables the "psychographic characteristics," taking into account someone’s "values, attitudes, perceptions, interests, expectations [and] satisfactions”. ${ }^{54}$ Hood believes it is the identification of these characteristics which distinguishes between visitor and nonvisitor populations. However, there are also groups of “occasional visitors,” such as organisation and club visitors, deserving of as much consideration as the other more obvious populations. ${ }^{55}$

The choices people make, leading them to fall into the visitor, non-visitor, or occasional visitor population, depend upon 'six major attributes underlying adults' choices in their use of leisure time.” These are identified by Hood as: being with people or social interaction, doing something worthwhile, feeling comfortable and at ease in one's

52 Doering, 2007, 339.

53 Doering, 2007, 340.

54 Hood, 2004, 150.

55 Falk and Dierking, 1992, 17. 
surroundings, having a challenge of new experiences, having an opportunity to learn, and participating actively. ${ }^{56}$ How a person perceives and prioritises these attributes, whether consciously or subconsciously, helps them make decisions surrounding their leisure time activities.

Drawing on ideas surrounding return visitation from Hood's studies, a section of all visitor research should be aimed at identifying the reasons and the expectations of people's visits to museums. ${ }^{57}$ Hood follows this by stating that if museums can provide thought-provoking and informative displays, they will foster return visits and enhance all visitors' experiences. She also argues that museums can then start to cater for unique perceptions and priorities, helping to make their venue a justifiable choice over the many other leisure activities available. McLean agrees, stating that, by incorporating these ideas, exhibitions will become connected two-way conversations, ${ }^{58}$ encouraging what Kotler calls "active engagement, immediacy, individuality and intense, memorable or unusual encounters". 59

McLean draws attention to visitors who are no longer the passive spectators of the past and now regularly "sit on exhibit-development committees, speak their minds in research and assessment programmes, and even contribute to visitor-generated exhibits and labels in exhibition galleries”. ${ }^{60}$ It follows that all visitors' agendas need to be carefully researched by museums so they can be directed with the view of creating suitable and worthwhile experiences. As Doering writes, “visitors make use of museums for their own purposes, and from varying perspectives. The museum can influence these outcomes but cannot control them”, emphasising a shift away from museums' aims, towards the visitors' desires. ${ }^{61}$

With regard to the discussions and theories on why visitors consciously choose to go to museums in their leisure time, Falk and Dierking have established what they call "The Interactive Experience Model”. This model is based on the interaction between an

56 Hood, 2004, 151.

57 Marilyn G. Hood, “Audience Research Tells Us Why Visitors Come To Museums - And Why They Don't Come,” (presented at the Evaluation and Visitor Research in Museums Toward 2000 Conference, Powerhouse Museum, Sydney, Australia, 1995), 2.

58 McLean, $1999,87$.

59 Kotler, 1999, 1.

60 McLean, 1999, 84.

61 Doering, 2007, 337. 
individual's personal, social, and physical contexts. ${ }^{62}$ The choices and experiences a person will have are dictated when these contexts interact. Falk and Dierking further maintain that whether a person visits museums regularly, or only to view a special exhibition, their "personal reservoir of knowledge, attitudes, and experience” will influence the encounter they have. ${ }^{63}$ If museums can recognise and respond to these agendas using visitor research, the agendas can be used to create more successful museum experiences. ${ }^{64}$ The personal agendas also determine whether visitors have the ability or inclination to fully interact with the exhibitions as the curators and designers intended. It is up to individual museums to work with techniques, such as Falk and Dierking's “Interactive Experience Model”, alongside their visitor research to decide how best to cater for their museum and their community.

\section{Museums' Goals and Visitors' Needs}

Traditionally, museums have focused heavily on their collections and associated exhibitions. Kotler believes this focus has led to museums overlooking the possibility that visitors may also be seeking "a contemplative space; a social encounter; a distinctive shopping experience; or a place where a family can spend quality time together”. ${ }^{65}$ The recognition of the social agendas surrounding an individual's leisure time activities has been undervalued. Kotler points out that museums need to know what encourages people to visit in the first instance, in order to move towards creating more social experiences which can be enjoyed in as many situations as possible. According to Kotler "sociability is a sought-after experience of visitors," which museums should capitalise on to help achieve success. This success combines formal and informal experiences, leading visitors to believe they are using their leisure hours wisely. $^{66}$

Visitor research is an essential part of work at museums as they become less exclusive, more accessible and promoted across all levels of society. However, there is still confusion over visitor research. Many museum professionals equate it with what

62 Falk and Dierking, 1992, 2-3.

63 Falk and Dierking, 1992, 37.

64 Falk and Dierking, 1992, 37.

65 Kotler, 1999, 1.

66 Kotler, 2001, 419. 
McLean calls a "give-‘em-what-they-want” style of market research. ${ }^{67}$ For Doering, the emphasis in evaluating the success of museums and exhibitions should be on the experience of visitors, rather than the goals of the museum staff. ${ }^{68}$ McLean states that this in turn can encourage curators and designers to question and update their own assumptions about their intentions and methods, as well as the visitors. ${ }^{69}$

Whether visitors make return visits and become regular visitors to a museum depends, to a great extent, on whether they make personal connections and see something of themselves displayed. Silverman notes that museums "must provide information and activities with reference to familiar and relevant concepts, particularly those from everyday life, so that visitors can make personal connections". ${ }^{70}$ Sharing concerns with Hood over a lack of repeat visitation, McLean states that building a sustained audience also means building participation in decision-making and meaning-making, activities which must take place in many ways over an extended period of time. ${ }^{71}$ To this end, McLean believes self-reflection is increasing among the many museums that are starting to ask what value their museum, as a civic institution, brings to the social mix. ${ }^{72}$

\section{Small Museums and Visitor Research}

It is generally agreed that defining the term "small museum" is problematic. Reibel has even claimed that "no one has ever successfully defined a small museum". ${ }^{73}$ However, Rowe and Barnicoat point out that there are several measures that can be used to define the size of a museum, depending on circumstances and requirements. Examples of these measures include visitation levels, the proportion of volunteers to paid staff, size of the collection, or annual budgets. ${ }^{74}$ These are all valid tools, but as Museums Aotearoa’s MANVS was the starting point for this research, and as an institution, Museums Aotearoa has also acknowledged that "one of the strongest issues ... [is] the need for

67 McLean, 1999, 87.

68 Doering, 2007, 338.

69 McLean, 1999, 87-88.

70 Lois H. Silverman, “Visitor Meaning-Making in Museums for a New Age," Visitor Studies 4 (1992): 165.

71 McLean, 1999, 103.

72 McLean, 1999, 85.

73 Daniel B Reibel, Registration Methods for the Small Museum, 3rd ed., (Walnut Creek, California: AltaMira Press, 1997), 8.

74 Paul Rowe and Wallis Barnicoat, "NZMuseums: Showcasing the Collections of All New Zealand Museums," in Museums and the Web 2009: Proceedings, ed. J Trant and D Bearman (presented at the Archives \& Museums Informatics, Toronto, 2009), accessed May 23, 2010, http://www.archimuse.com/mw2009/papers/rowe/rowe.html. 
practical advice and support to be available for smaller museums”, their measure of defining size was chosen. ${ }^{75}$

Furthermore, the practical guides which have been published on visitor research do not take into account differences in museum size or availability of resources. They often appear to take a "one-size-fits-all” approach. Therefore, when it comes to looking at visitor research specifically with small museums in mind, there is little information available which is not generalised. There have been books and guides published of a practical nature designed to help any museum understand why visitor research is important and how they can undertake it effectively and efficiently. To this end, there are resources available with titles such as "Museum Visitor Services Manual” edited by Roxana Adams, or “The Engaging Museum: Developing Museums for Visitor Involvement” by Graham Black. There are also useful step-by-step guides entitled 'Know Your Visitors’ and 'Introduction to Visitor Surveys' available from National Services Te Paerangi’s website.

However helpful these generic visitor study guides might be, Reibel insists professionalism and local knowledge are the most important ways museums can work together to improve their standards and experience. ${ }^{76}$ Additional professional services can sometimes be within reach of these museums from within their communities. Kotler argues that locals employed within fields such as public relations, marketing, or accounting may be willing to assist if approached in an appropriate manner. ${ }^{77}$ Following on from this argument, it is within the small museum's grasp to energise the creativity and vitality of their board and staff, helping to "increase the number of volunteers, involve community members, and become a more valued and viable part of [their] community". ${ }^{78}$ This can be seen as a powerful resource available to the small museums that understand and embrace the concept of expertise pooling and knowledge sharing.

According to Spinazze, there are several themes which frequently emerge when small museums try to carry out visitor research. The first centres on how many of these museums rely heavily upon volunteers. High turnover of the volunteer staff prevents

75 Museums Aotearoa, 2005, 13.

76 Reibel, 1997, 8.

77 Kotler and Kotler, 2008, 26.

78 Alice Parman and Jeffrey Jane Flowers, Exhibit Makeovers: A Do-It-Yourself Workbook for Small Museums (Plymouth, United Kingdom: AltaMira Press, 2008), 1. 
consistency; moreover many of the volunteers claim to be daunted by change and technology. Spinazze also points out that despite the importance of information technology (IT) to museums globally over the past 20 years, its use remains limited in the small museums. ${ }^{79}$ Rowe and Barnicoat agree there is little or no IT infrastructure within small museums, usually due to a lack of money and expertise. ${ }^{80}$

Spinazze discusses the use of IT as a part of museums' "information ecology". This, as a concept, is characterised by a museum’s professional staff “working with limited resources, guided by professional and ethical standards, engaging in object care, display and interpretation and incorporating technology as a means of assistance with daily administrative and communications activities". ${ }^{81}$ She states that it is the stability within this "information ecology" that is vital to the successful management and running of a museum. Large museums are able to take much of this for granted, their resources will be available when needed and work as required. However, the limited resources available to small museums mean technology is more difficult to acquire and keep up to date.

It therefore becomes evident that there are many challenges facing the running and improvement of small museums which can be argued to be historical issues, having not come much closer to resolution over many years. However, despite these challenges, there are also many benefits to being a small museum. These need to be recognised and utilised to their full potential. The benefits, discussed below, can go some way to helping fill the gaps of the previously noted challenges. While large museums are fewer in number, they are able to use their high profiles to capture funders' and the public's attention. However, Harrison Kubany and Stephens remark there has been a trend in the proliferation of small museums that have the ability and desire to concentrate on single subjects, creating points of interest by including the unusual and unexpected. ${ }^{82}$

It is not surprising that many small museums have been created around these specialised collections. Harrison Kubany and Stephens assert that the reason this is successful is because there is a "desire for an immediate connection with the work on display [which]

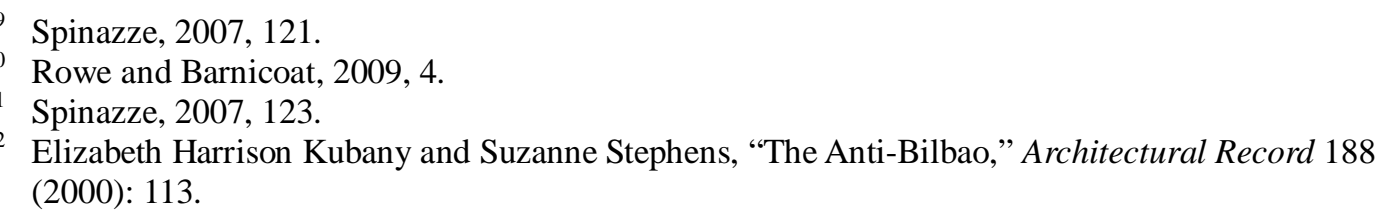


requires a scale available only in an intimate space ... [and] a more active relationship with their communities than the traditional static museum designed for passive viewing”. ${ }^{83}$ Reibel importantly points out that small is not a euphemism for poorly run, instead meaning the "size and complexity of the collection can be grasped very easily, and be of a dimension where even a small staff can handle it". ${ }^{84}$

In opposition to the large institutions, McNichol's opinion is that small museums have less bureaucracy to deal with and are therefore better placed to make quick decisions. These decisions can lead to fast and comprehensive actions which play to strengths and deliver high level services. ${ }^{85}$ Small museums are able to respond well to approaches that are holistic and systematic, relating well to their most important attributes of "agility, responsiveness, and flexibility in the face of ambiguity and uncertainty”. ${ }^{86}$ As community institutions, McNichol describes small museums as the "creative and visionary non-profit-organisations that continuously strive to meet the needs of the communities they serve". ${ }^{87}$

It is generally accepted that small museums are an important part of communities which are able to embody a sense of place affecting visitors. Harrison Kubany and Stephens emphasise that this is while working within modest missions and using accessibility, special programmes, considerable regional knowledge and specialities to reach out to create local pride. ${ }^{88}$ By embracing this concept, many small museums are finding success in becoming the "loci for fragmented communities otherwise lacking a physical space for cultural expression”. ${ }^{89}$ Kotler and Kotler also note that events and public programmes are highly valuable for small museums in building membership and raising money. ${ }^{90}$ Despite the hard work that many museums have undertaken to increase their community standings, McNichol believes they must still "market themselves very strategically to attract audiences and maintain a position in the future". ${ }^{91}$ All museums must acknowledge the importance of visitor research to maintain and improve their position in the expansive and competitive leisure industry.

83 Harrison Kubany and Stephens, 2000, 113.

84 Reibel, 1997, 8.

85 McNichol, 2005, 241.

86 McNichol, 2005, 240.

87 McNichol, 2005, 241.

88 Harrison Kubany and Stephens, 2000, 113.

89 Harrison Kubany and Stephens, 2000, 113.

90 Kotler and Kotler, 2008, 26.

91 McNichol, 2005, 239. 
However, Hooper-Greenhill acknowledges that visitor surveys are not, or are very rarely, carried out in museums with fewer resources because of limited staff and funding, as well as inconsistencies in general practice. ${ }^{92}$ McNichol agrees that visitor research can only play a reasonably minor role in small museums. She argues that even if these museums were in possession of resources for traditional research methods, such as interviews or surveys, these methods require both business acumen and intuition, which are lacking in many of the small institutions. ${ }^{93}$ McNichol believes that, by realising these limitations, small museums can become more businesslike in their management and marketing, by looking to pool local expertise and share skills and experience. ${ }^{94}$ McLean recognises this may be difficult, but claims it makes for far more interesting museums: "by embracing the tensions inherent in a dialogue, we will better understand how each form of knowledge informs the other, and, most importantly, we will become better able to articulate our issues in common”. ${ }^{95}$

\section{Summary}

Traditionally, some museums have had trouble undertaking visitor research as they deal with practical issues that supersede any theoretical preferences. The literature emphasises how museum practice needs to embrace theory to help prove museums' value, which in turn helps to justify funding. There is value in ascertaining more about visitor experience. Museums need to understand visitor research and how to use it to discover their visitors' social agendas, improve their exhibition development, and locate their place in the leisure-market. If museums are able to embrace the tensions found between the theory and practice of visitor research, then, McCarthy and Labrum argue, this "contradictory, ambivalent, position which museums are in [will make] them key cultural loci of our times". ${ }^{96}$ By keeping in mind the common tensions between theory and practice, it becomes possible to explore the practical achievements of small museums, as well as looking at ways theory might help to enhance their practice. Therefore, practice and theory are not mutually exclusive and better understanding their connections can be of benefit to both museum professionals and scholars. In this way,

92 Hooper-Greenhill, 2006, 368.

93 McNichol, 2005, 241.

94 McNichol, 2005, 239.

95 McLean, 1999, 105.

96 Conal McCarthy and Bronwyn Labrum, "Museum Studies and Museums: Bringing Together Theory and Practice,” Te Ara 30 (2005): 6. 
theory needs to inform practice, explaining why visitor research is important.

The next chapter explains what my research involved and how it was carried out, focusing on answering the question of what the needs are of small museums with regard to visitor research, as well as looking to identify how these needs might be met within a New Zealand context. Chapter Three then expands individually upon the seven interviewed institutions. Here, the museum/gallery type is explained, along with staff numbers, governance structure, and location. Their views of visitor research are also outlined, as well as visitor research undertaken in the past and what barriers they have found to carrying out further visitor research. Following on from this, Chapter Four identifies the common themes raised across the interviews. These include current practice, perceived benefits, and barriers to visitor research. There is also a section addressing the ways in which the understanding of visitor research could be expanded within small museums. Finally, Chapter Five lists the conclusions reached. These conclusions outline ways in which the visitor research needs of small museums might be met, including implications for support and guidance, as well as recommendations for further study. 


\section{Chapter Two: Research Design}

\section{Introduction}

This chapter firstly explores my research question before looking at the methodology I employed to answer this question. It also considers the ethical implications necessary to ensure the rights of the research participants were protected. The research population from which I sampled is also explained, as well as information about the sample itself. The limitations of the research are then laid out, followed by a brief discussion on the analysis of the research findings.

Museums Aotearoa acknowledges that many small museums are unable to meet satisfactory standards of professional museum practice. This means that there is a need for a high degree of co-operation and mutual support, ${ }^{1}$ support which is "practical and appropriate for their needs". ${ }^{2}$ The area I identified as needing support was the field of visitor research, thereby centring my research on the question: what are the visitor research needs of small museums and how can these needs be met? My research focused on visitor research because I wanted to assess the extent to which small museums are able to carry it out, while exploring its importance for different museums in terms of its perceived value, the effectiveness of its implementation, and varying uses of the collected data. Recommendations could then be developed to look at ways in which small museums might be helped when undertaking visitor research.

In terms of the research practice of small museums I was interested in how they undertake visitor research, what their current research practices involve and what issues they may have faced in the past. To do this I undertook seven face-to-face interviews with staff from seven museums and galleries over a two week period in November 2010. Within these interviews, I investigated certain themes. The first theme explored the perceived value that the interviewees had of visitor research, looking into their current practice and ways to overcome barriers preventing visitor research. The second theme was concerned with addressing the museums' relationships with their visitors and communities. These relationships were examined by asking whom the museums see 
themselves as serving, as well as what specific experiences, if any, they hope to provide. In order to explore this, questions were focused on the museums' perceived relationships with their visitors, and where they fit within their communities.

It was also necessary to investigate funding and resources, both for carrying out the research as well as for reporting back to governing bodies. This was done by asking whether reporting to their governing bodies requires visitor research, and if they receive any support (financial and in-kind) to do visitor research. The question was also raised as to whether or not funding and other resource support could be increased by using visitor research to enhance reporting or complete funding bids.

\section{Methodology}

The methodological considerations for carrying out this research meant there were three types of approaches to be examined. These approaches consisted of quantitative, ${ }^{3}$ qualitative, ${ }^{4}$ and a mix of these methods. Creswell helpfully describes these different methods as located along a continuum, rather than being opposing views. He states "a study tends to be more qualitative than quantitative or vice versa", while "mixed methods research resides in the middle of this continuum". 5

The selection of a research methodology depends upon which methodology best suits a researcher's purpose, dictated by their research questions. When determining which methodology to use, the first consideration is that of understanding what worldview assumptions, or "basic set of beliefs that guide action", you hold as the researcher. ${ }^{6}$ These worldviews tend to be reflected in the methodological choices made. I chose to undertake qualitative research, which can be explained as reflecting a worldview based on social constructivism. This view holds "assumptions that individuals seek understanding of the world in which they live and work" and the "goal of the research is to rely as much as possible on the participants’ views on the situations being studied”. 7 This methodology focuses on the use of open-ended questions and flexibility, suiting the

3 Quantitative research is concerned with gathering large amounts of data which can be used statistically, using methods such as surveying.

4 Qualitative research is composed of in-depth research which tries to understand behaviour, utilising methods such as interviewing or focus groups.

5 John W. Creswell, Research Design: Qualitative, Quantitative, and Mixed Methods Approaches (Thousand Oaks, California: Sage Publications, 2009), 3.

6 Creswell, 2009, 6.

7 Creswell, 2009, 8. 
research I planned to undertake, that being to increase my understanding of small museums and their visitor research needs.

A mixed methodological approach was also a useful consideration, in which "inquirers draw liberally from both quantitative and qualitative assumptions”, using any method available to find a solution to the problem. ${ }^{8}$ Museums Aotearoa's scoping survey was a quantitative survey and one of the catalysts for my research. The survey was composed of a large, nationally representative sample and analysing the data implied issues within the visitor research being undertaken by small museums. It was these results which appeared to warrant the in-depth, qualitative investigation I undertook, discussed further in Chapter Four.

Recorded face-to-face interviews were the ideal format for this in-depth research. Within qualitative research, interviewing is one of the most common methods. The process should always be related to a specific question and purpose, helping avoid bias and distortion. ${ }^{9}$ I guided my interviews with interview questions which were sent to each interviewee in advance for their consideration (see Appendix A). The interview guide was carefully created after asking myself questions to ensure only relevant information was requested (such as: what information will these questions provide, and are these questions leading?). Although I used a semi-structured interview guide, each of the interviews was unique, and it was my intention to add to the questions depending on what interviewees knew and were willing to share. ${ }^{10}$ This meant the interviews allowed opportunities for expansion and clarification by myself and the participants.

\section{Ethics}

Ethical research can be broadly defined as "doing no harm." ${ }^{11}$ Benefits to research subjects must always outweigh perceived potential burdens. For example, any possible benefits to other members of society can never justify harming a research subject. ${ }^{12}$ Codes of ethics have come to centre on ideas surrounding the informed consent of all

8 Creswell, 2009, 10-11.

9 Sotirios Sarantakos, Social Research, 3rd ed. (Basingstoke, Hampshire: Palgrave Macmillan, 2005), 177.

10 Herbert J. Rubin and Irene Rubin, Qualitative Interviewing: The Art of Hearing Data (Thousand Oaks, California: SAGE, 2005), 4.

11 Heather Piper and Helen Simons, “Ethical Responsibility in Social Research,” in Research Methods in the Social Sciences, eds. Bridget Somekh and Cathy Lewin (London: SAGE, 2005), 56.

12 Piper and Simons, 2005, 15. 
research subjects, the acknowledgement of the uses of the research, as well as guarantees of privacy and confidentiality. Privacy, confidentiality or anonymity can be crucial factors in any subject's decision regarding whether or not to participate in research. It is then up to the individual researcher's moral judgements to maintain the spirit of what was agreed with the participants. In the case of my research this agreement was governed by the conditions agreed upon with the Victoria University of Wellington Human Ethics Committee (VUW HEC) (see Appendix B).

The agreement I reached with VUW HEC centred on the research being confidential, not anonymous, with informed consent obtained in writing from all participants. I endeavoured to ensure confidentiality was met by not naming individuals or their place of work or location. However, it was acknowledged there can be difficulties with omitting all potentially identifiable details. Therefore, all interviews were transcribed and sent to interviewees to be checked, agreed upon, and edited if necessary. This process allowed participants the opportunity of adding information or deleting statements they did not want included in the research. Interviewees also had the opportunity throughout the research process of withdrawing themselves and their data at any time they chose, up to a given date.

Informed consent was therefore a vital consideration, ensuring every research subject interviewed had knowledge of my motives and purpose. There were also opportunities to ask questions, withdraw from the research, check their transcript, be assured of confidentiality, and have knowledge of the uses of the information, its storage and protection (see Appendix C). This allowed interviewees to make informed decisions as to their voluntary participation. It was vital that participants were happy with the informed consent statement and fully understood it, due to potential implications for how they answered questions.

While always working within the ethical guidelines ensuring participants' privacy, I knew I would be interviewing people who belong to fields of work or areas of interest which may be too small to be able to safely guarantee anonymity. Although I strived to provide the highest levels of confidentiality and respect privacy, if there were any concerns I planned to explore ways of offering alternative research procedures. 
However, this was not necessary. ${ }^{13}$

\section{The Research Population and the Sample}

As only Museums Aotearoa members were included in the original scoping survey and only members will be asked to contribute to MANVS, my sample was made up of a sub-set of the original population. Due to the intention of my research focusing on visitor research needs of small museums, Museums Aotearoa supplied a list defining the size of their museum and gallery members based on staff numbers. The list outlined 166 Museums Aotearoa members, from a total of 465 museums and galleries in New Zealand. This included 54 micro museums, 74 small museums, 30 medium museums, and 8 large museums. I then identified 15 small institutions within one region of New Zealand to potentially be interviewed.

It was decided a maximum of eight interviews would be conducted due to time restrictions. Four institutions were removed from the sample pool: two due to the fact they were undergoing renovations, and two due to the distance required to travel to the interviews. Eleven invitations for interviews were emailed out, resulting in seven acceptances and two apologies. The remaining two institutions did not respond and could not be reached by phone.

The invitations consisted of a letter outlining the research (see Appendix D) and asking whether the institution would be willing to participate in an interview. The interviews were subsequently carried out with managerial staff nominated by the museum or gallery and held within their premises. Although one of the museums interviewed had no full time staff and was therefore a micro museum, they did have a part time manager who was a museum professional. There were no micro museums interviewed that relied upon volunteer labour, as they require a different level of assistance than this research was able to explore.

Although a small sample was used for this research, there was diversity and it covered a range of perspectives. In this regard, Gilbert emphasises that all "research ultimately must be based on comparisons, whether it be comparisons between different groups of cases, between the same cases at different points in time, or even between what is and

13 Sarantakos, 2005, 20. 
what might have been”. ${ }^{14}$ These opportunities for comparison included size, location (rural or urban), the type of museum or gallery, and general reporting and accountability, all discussed further below.

\section{Size}

Although my intention was to interview only small museums, during the process of interviewing it became apparent that two institutions had more staff than expected and were actually medium-sized museums. I had used data collected by Museums Aotearoa at an earlier time and it was only when the museums were asked to confirm their staff numbers that it became apparent they were bigger than expected. At this point it was too late to rule them out as there were no alternatives available. However, having a sample which included small and medium museums was useful for comparative purposes, for example to explore whether size is a factor in determining differences in the perceived value in conducting visitor research, as well as what they are able to undertake. Differences might also be evident within the level of support received from management and funders to carry out visitor research.

\section{Location}

The location of the organisations was also considered. Two rural institutions were interviewed. This was because their interviews could provide comparisons with the urban institutions, such as identifying if there were differences in their roles within local communities.

\section{Type of Museum/Gallery}

Different institution types may hold differing views on the value of visitor research. Interviewing three art galleries and four museums (two of which are also historic buildings) meant comparisons with visitor relations could be explored. This exploration included aspects such as whether they are aware of who their visitors are and why they might choose to visit.

\section{Reporting and Accountability}

How organisations grow and prioritise the work they do is often governed by a Strategic

14 G. Nigel Gilbert, ed., Researching Social Life, 3rd ed. (Los Angeles: SAGE, 2008), 325. 
Plan. A Strategic Plan helps to clarify a museum's vision for the future and guide the decision-making process over a certain period of time. Reporting is a necessary component of this process, providing proof in various forms which outline appropriate progress being made. Therefore, it is interesting to consider the role of the visitor and visitor research within these plans. The fact that one of the institutions interviewed has no Strategic Plan is an important consideration for comparative purposes. This raises the question of what goals governing bodies have for museums and galleries and why visitor research is often not required to feature in their reporting.

The table below gives an overview of the institutions interviewed, which are all described in more detail in the next chapter:

\begin{tabular}{|l|l|l|l|l|l|}
\hline & $\begin{array}{l}\text { Small or } \\
\text { Medium }\end{array}$ & $\begin{array}{l}\text { Museum, } \\
\text { Gallery or } \\
\text { Historic Building }\end{array}$ & $\begin{array}{l}\text { Urban } \\
\text { or Rural }\end{array}$ & Governance & $\begin{array}{l}\text { Strategic } \\
\text { Plan }\end{array}$ \\
\hline Interview 1 & Small & Gallery & $\begin{array}{l}\text { Udvisory } \\
\text { Board }\end{array}$ & Yes \\
\hline Interview 2 & Micro & $\begin{array}{l}\text { Museum / } \\
\text { Historic Building }\end{array}$ & Urban & $\begin{array}{l}\text { Board of } \\
\text { Trustees }\end{array}$ & Yes \\
\hline Interview 3 & Small & Gallery & Urban & $\begin{array}{l}\text { Board of } \\
\text { Trustees }\end{array}$ & Yes \\
\hline Interview 4 & Small & Museum & Rural & Manager & No \\
\hline Interview 5 & Small & Gallery & Rural & $\begin{array}{l}\text { Board of } \\
\text { Trustees }\end{array}$ & Yes \\
\hline Interview 6 & Medium & Museum & Urban & $\begin{array}{l}\text { Board of } \\
\text { Trustees }\end{array}$ & Yes \\
\hline Interview 7 & Medium & $\begin{array}{l}\text { Museum / } \\
\text { Historic Building }\end{array}$ & Urban & $\begin{array}{l}\text { Service } \\
\text { Group / } \\
\text { Manager }\end{array}$ & Yes \\
\hline
\end{tabular}

Table 2: Summary of characteristics of institutions where interviews were conducted

\section{Limitations}

Despite the diversity described above, I have identified some ways in which my research is limited. Firstly, I only interviewed museums and galleries which could be accessed using public transport. This physical practicality, plus time restrictions, meant the sample size was small with seven interviews conducted. Caution must therefore be applied as the sample was not nationally representative. The results can be reflected upon, but cannot be assumed to apply to other museums or galleries. 
In addition, different types of funding could lead to differences based around accountability. As mentioned earlier, the needs of micro museums that have no paid staff were not addressed. These institutions often rely on volunteer support for all of their activities. Where there are no museum professionals available, different levels of guidance and support might be required.

\section{Analysis}

When analysing research data, reflexivity is a device often employed to help explain, with reference to the researchers and their own lives, research motives. Reflexivity is achieved through the consideration of a disciplined self-reflexive approach to one's own behaviour. ${ }^{15}$ Researchers who justify their findings in ways which show how their opinions have been shaped by other relevant experiences can be seen as constructing carefully considered conclusions. These conclusions are better-rounded and open to improvement through interpretation and critique. For me to acknowledge ways in which my collected data has been interpreted, I must reflect upon Museums Aotearoa, VUW and the MANVS pilot. It was while I worked on this pilot that I noticed a lack of variety within visitor research, especially for small museums. This observation raised concerns for me about small museums' understanding of visitor research in general and the benefits it can have for their institutions.

With this in mind, the analysis of my interviews has been thematic, based on grouping the interview questions into a form reflecting the research question. These groupings were focused on current and ideal practice, funding and management, and community value and involvement in the museum. It is worth noting that this research is based on my interpretation of what the interview respondents said. I have endeavoured to make it as accurate as possible, while fairly representing the people and institutions interviewed.

\section{Summary}

In this chapter I have explained my research question and the methodology I employed to answer it. Ethical implications for the research and the sample have been outlined, along with the limitations and the analysis of the findings. These findings have come from the data provided by seven interviews. Each interview is represented in the next

15 Piper and Simons, 2005, 58. 
chapter individually, detailing the institutions they represent, plus their visitor research contexts as I understand them. A chapter on the common themes raised across the interviews then follows, exploring the benefits and barriers which arose. 


\section{Chapter Three: Interviews}

\section{Introduction}

This chapter presents the findings from the seven in-depth interviews. It begins by detailing the interviews conducted with the participating museums and galleries, including sections on: what type of museum or gallery they are, staff numbers, governance structure, and location. There are also visitor research specific sections summarising the institutions' views on visitor research, the range of visitor research they have undertaken, and barriers they have encountered.

The purpose of including these interviews individually is to describe the physical characteristics of the institutions and outline each of their attitudes towards visitor research. In this way a picture is built up of the context in which each of these museums and galleries operate, as well as their experiences and expectations surrounding visitor research. Each interview has as much detail as possible included. However, in some cases the information may seem vague, as it cannot be more specific without breaching confidentiality as discussed in the previous chapter. Following the interviews, common themes and issues are identified.

\section{Interview 1: Urban Art Gallery}

\section{Museum/Gallery Type}

This institution is an urban art gallery with free entry and opening hours of Tuesday to Sunday, 11am to 5pm. The Director does not focus on attracting large numbers of visitors to the gallery, instead is working on building a reputation with art professionals throughout the world, using the gallery's networks and the personal connections of the members of staff. They promote their profile and reputation using carefully placed national and international advertising. The esteem received from this targeted art audience is considered as important as visitation from them:

The whole reputation of an institution can be brought down if people decide that it isn't any good and isn't performing. What I'm really keen to do is to build the opposite. So people say that we're doing great things, even if they don't come. That builds a profile and a reputation you can be proud of, rather than being on the back-foot and always being criticised whatever you do. 


\section{Staff Numbers}

The current staffing level at this institution is 3.4 FTE. Over the three years that the Director has been employed the number of staff has increased from a single position. In addition there is a pool of approximately 60 volunteers, who perform various duties such as staffing the front desk during the week:

I had to build a team as I didn’t have any permanent staff when I started. ... The current staff consists of the Director, the Assistant Curator, an Exhibition Officer, a Collection Officer, and a two day a week Administrator.

\section{Governance Structure}

The Director of this gallery is required to report quarterly to an Advisory Board outlining the gallery's activities and visitation numbers since the last report. This Board is made up of seven people who have knowledge and experience in areas such as art history, museums, and managing galleries. Their funding comes directly from the large organisation within which the gallery sits:

I have an Advisory Board, who does not make decisions, but I report to them and they advise me. It's a way of getting feedback and support, as well as community buy-in, both the local community and the wider community.

\section{Location}

Despite being located in an urban environment, this gallery considers its location a problem due to not being in the centre of town. To mitigate this, the gallery has attempted to extend its reach by providing public programmes in different locations around the city. They also use their website to provide a different type of experience, such as access to recorded talks given at the gallery, as well as archiving their past shows:

Just where we are will always be an obstacle. But what we have done in the past is take our activities out into the city. We've done things at other locations, or on the streets, so we've taken the art or some of our public programmes to them if they can't come here. And that's why I really value the website, because people can follow what we're doing without physically coming here.

\section{Views on Visitor Research}

There has been no visitor research undertaken within the past three years, beyond gathering visitation numbers. However, the Director acknowledges visitor research 
would be undertaken if the Board expected it. Otherwise it may not be prioritised unless a specific need is identified. Any future visitor research would focus on the satisfaction of the visitors' experiences, suggestions for improvements, and possible exhibition ideas:

If our Board expected more people to come through the door and did some number crunching and decided that we were uneconomical, we would certainly want to find out ways and strategies for getting more people in. I think there is probably a useful body of research we could do to find out what people want, what they've enjoyed and why.

\section{Visitor Research Undertaken}

With regard to reporting to their Board, visitation numbers and anecdotal feedback (from emails and other correspondence) are considered sufficient visitor information by both the Board and the Director. The visitation numbers are recorded on a manual, hand-held clicker by whoever is staffing the gallery:

I write a Director's Report that explains our activities over [every] three month period and we compile a dossier of information of everything that's been published about what we've done, every bit of copy that's gone out. We also provide numbers, and we give anecdotal feedback.

\section{Barriers to Visitor Research}

The minimal visitor research requirements for reporting, along with the reported high workload of the staff and lack of experience in conducting visitor research, means additional visitor research has not been prioritised:

I guess our priorities have been elsewhere, it's not just 'we haven't got any money, but it's something we should do'. Since I've been in the position there have been some basic strategic issues that I've had to deal with in terms of getting a vision in place for the institution and getting a whole lot of policy documents and idea documents in place.

\section{Interview 2: Urban Heritage Building/Museum}

\section{Museum/Gallery Type}

This is an urban museum which has an entry fee. It is open daily during summer from $10 \mathrm{am}$ to $4 \mathrm{pm}$, and throughout the rest of the year is open Saturday and Sunday from $12 \mathrm{pm}$ to $4 \mathrm{pm}$. The museum has a social history focus, based around its building, which is an important part of the story. The museum is going through the beginning stages of a redevelopment and the interview was conducted with the newly appointed Manager:

This is a social history museum based in a major city ... and is also an 
important heritage building built in the mid-nineteenth century, so it has quite a strong history of early colonial, European history in New Zealand.

\section{Staff Numbers}

The museum employs the Manager, who works half-time, as well as four part-time museum hosts/tour guides, and two volunteers. There are other resources available due to the museum being part of a collaborative group of museums in the area. This includes access to skilled people to help with maintenance and exhibition ideas:

Luckily for me, the museum is a part of a wider network of museums. That means I have access to these other people: their experience and skills, practical knowledge and labour and all of that. Otherwise, running the museum part time on my own would be a bit hard.

\section{Governance Structure}

This museum reports to a Trust Board which is a Council Controlled Organisation (CCO), where the Council is the main funder and appoints the trustees. The Trust Board is composed of five trustees, with skills and experiences ranging from arts to business. Important components of the museum's reporting are visitation numbers and visitor satisfaction. However, as the Manager is new to the position, s/he is not able to elaborate further:

We report to a Trust. We report on visitor numbers and customer satisfaction. I presume they print out the results from the opinion-meter ${ }^{1}$ and turn that into some sort of report. It's mostly been ticking over, waiting for the previous manager to retire and the redevelopment to occur. Obviously we need more people answering the survey [approximately 30 per annum], but it's currently reported as it is.

\section{Location}

Although an urban museum, its location is on the outskirts of the city centre. This is believed to have affected the visitation, but it is hoped that the redevelopment might help address the issues. There are many possibilities regarding the redevelopment which will hopefully generate interest by collaborating with different groups, such as historical societies and contemporary artists:

I've just come into this role and am facing a redevelopment of the museum. So it's a bit tricky as we don't know what's going to happen to it ... It's all up in the air, but we are trying to modernise it and increase the experience.

1 An opinion-meter is a touch-screen computer that allows visitors to complete self-complete surveys. 


\section{Views on Visitor Research}

The Manager is enthusiastic about rectifying the current lack of visitor research and wants to discover who the museum's visitors are, their expectations, their experiences, as well as suggestions for improvements. Within a few months of this interview, s/he is planning to undertake face-to-face surveying to help inform the redevelopment:

I'm going to undertake some visitor research myself as I have a background in visitor research. And in terms of the redevelopment plan, we'll want to find out some specific information from people. This will be done using face-to-face interviews ... At this stage, the visitor research is pretty thin on the ground, but it's going to get better.

\section{Visitor Research Undertaken}

Currently the museum staff record visitors' basic demographic information in a ledger upon their arrival. This information includes gender, approximate age, and group composition. There have been attempts to collect additional visitor information, such as satisfaction levels, in an irregular manner using their opinion-meter. However, the Manager has noticed none of the collected data appear to have been analysed or used for any purpose beyond the required reporting to the Trust Board:

We take basic visitor information in the ledger book. This includes gender, as well as age groups using: children, 18 to 35, 36 to 60 and 60 plus, which are estimated by the staff members. There's also whether the visitors are independent or group/education visits, and that's about it. ... I don't think there's been much luck with finding out the demographic, given that so few people have used [the opinion-meter].

\section{Barriers to Visitor Research}

Regular and ongoing face-to-face surveying is a priority for the Manager. Despite a reported lack of time and resources the Manager is positive and dedicated to making sure consistent data collection is achieved:

I have done a lot of visitor surveys in the past, so I'm skilled enough to do it. The only thing is the resourcing, so it might be worth looking at getting other people in to help, like students. ... That's probably the biggest issue actually, having the time and resources to do them and then analyse them, and then evaluate them to see what we can do with the results. But we'll get around those. 


\section{Interview 3: Urban Art Gallery}

Museum/Gallery Type

This interview was with an urban gallery which has free entry and is open 10.30am to $4.30 \mathrm{pm}$ daily. The gallery is a registered Charitable Trust, set up with the purpose of supporting, advancing and educating New Zealanders using New Zealand art.

Therefore, the gallery's exhibitions have a New Zealand focus, but involve a variety of themes and styles:

We would describe ourselves as an art gallery, including sculpture and objects that represent New Zealanders. ... We're a unique gallery because we have stories in the form of art, or panels, or catalogues. We're presenting art and the stories behind the art, and in that way we're unique.

\section{Staff Numbers}

The gallery employs a full-time Director, five part-time staff, and an additional six volunteers who assist with installation and de-installation of exhibitions. There is also an extensive 'Friends' group, numbering over 400. This is a group of people who are willing to provide services and labour for events, such as exhibition openings:

We have volunteers who staff the reception desk. But our involvement would mainly be our 'Friends' group. We have a strong group who started at the gallery's inception around 1990. They've been involved in setting up exhibitions and that's where our roots are. The 'Friends' are now a more formal sort of group, with a secretary running it.

\section{Governance Structure}

The gallery has no formal sponsor to provide their operational budget, currently relying on smaller sponsors and fees from their 'Friends' group. In accordance with the gallery’s status as a Charitable Trust, they are governed by a Board of Trustees. There are ten trustees who have the knowledge and experience to assist with financial and managerial matters. The Board expects reporting on visitation numbers and general feedback from visitors. There have also been committees formed to further assist with the development of the gallery:

Our Director is required to report to the Board of Trustees. Visitor numbers are required in that reporting. ... We're going down the lines of looking for a formal sponsor and fundraising, and have set up a Sponsorship Committee. Plus there's the Programme Committee who plan for the long term exhibitions.

\section{Location}


A year ago this gallery moved to a new central city location, before which it had limited space in which to exhibit as it was based out of different offices:

Prior to our current home, we've been operating out of various places. That we now have a 25 year lease on our present residence means we have a permanent place, but this has only been so this year.

\section{Views on Visitor Research}

Once the institution acquires a formal sponsor they believe visitor research will be a useful exercise to undertake. Visitor research will help them prove themselves as an institution worthy of current and future funding:

We would most definitely consider [visitor research] in the future. I think it's a good way that you can prove yourself. But we'll probably not be able to do it until we have an operational budget and we can support that sort of research.

\section{Visitor Research Undertaken}

The gallery staff record visitation numbers using a manual, hand-held clicker at the front desk. The gathered numbers fulfil the gallery's reporting requirements for their Board. There is also a suggestion box, from which suggestions are collected and carefully considered. In the past, suggestions have led to practical changes and exhibition ideas. There is also ongoing reflection on informal feedback provided by visitors. The gallery understands the value in working with visitors' interests as these interests can help create exhibitions with ready audiences:

This is something that small institutions can do well because the feedback may not be formal, but it is direct and there are consequences to people commenting. ... Anecdotally we know some information about our visitors through our supervisors, who are in the gallery on a daily basis.

\section{Barriers to Visitor Research}

A lack of money is seen as the main barrier to undertaking the visitor research. The gallery staff believe visitor research can help prove the gallery's value, but do not think it is something that can be achieved with the staff they can currently employ:

We have no operational budget and no staff that would be able to undertake that sort of research. So, money and cost would prevent us. ... You've really got to have an operational budget, so that's what we're really working towards as part of our long term goal and strategy. 


\section{Interview 4: Rural Museum}

\section{Museum/Gallery Type}

This museum is a free rural museum, which is open to the public Wednesday to Saturday, 10am to 5pm. It started its life as an institutional museum, only opening to the public around fifteen years ago. The museum has a unique theme, which has been defined by its local community and their activities:

This museum is the place where we can tell real life stories of certain aspects of New Zealand's history, a place to learn about contemporary issues as well as the past. And we have amazing objects and stories to do with pivotal moments in New Zealand's history.

\section{Staff Numbers}

The museum employs three FTE staff, two part-time staff, as well as having five volunteers available. This level of staffing means there is a lot of involvement by the Director in day-to-day operations of the museum. The Director believes there is the need for more external, practical support for directors of small museums, to help them prioritise work and become more efficient with their limited resources:

Directors of small museums are way too involved in the day-to-day operation of their museums, but how do you escape from that when you only have three staff? It's really hard work and I feel a bit burnt out by it actually.

\section{Governance Structure}

There are no requirements to report on visitation and the museum has no Strategic Plan to follow. The Director has a Manager from within the large institution which provides all of their funding. This Manager does not require any reporting from the museum, partly due to the museum's unique character. However, the Director of the museum understands how this lack of accountability can be restrictive, especially in terms of growth. The museum has worked hard to prove itself to the stakeholders and the community:

It's been an ongoing battle for the last ten years because we're so different from all the other business groups and activities that our stakeholders do, and there are different priorities as we're such a small piece of their billion dollar pie. Because of our size and where we sit in the organisation we just don't meet the thresholds for them to take notice. 


\section{Location}

The museum is located outside a small city. There are issues around increasing visitation due to the remote location. Currently, their visitation heavily consists of school and education groups. However, they are trying to make the museum feel more welcoming to encourage ‘drop-in’ visitors:

Most of our visitors are through booked tours or education and school groups. There aren't many drop-in people, as our location possibly puts off a lot of people. So with the building, we've tried to make it more inviting.

\section{Views on Visitor Research}

Detailed visitor research, such as face-to-face surveying, has been undertaken by the museum in the past. The Director sees the value in what the data can provide, particularly how it helps to justify the museum and improve exhibitions and services. The Director also believes being accountable is important, stating that if the museum had to be more accountable to its stakeholders, it would help the museum argue their case for increased funding and staffing:

[We undertook visitor research because] we wanted to know what we were doing right and what we were doing wrong, what people were actually getting, what we might do better for the future. ... I've done quite a bit to raise the profile of the museum so there are more expectations of the museum to do things now, where there wasn't in the past. I'm hopeful that in the future we'll have to become more accountable, which will help with getting more staff and funding.

\section{Visitor Research Undertaken}

Currently, visitation numbers are recorded through the cash register as visitors arrive (although visitors do not pay to enter). Unspecified demographic information was also recorded by the museum in the past. This activity was discontinued around a year ago as there was no time for proper analysis. There has also been some face-to-face surveying completed, but this was restricted by finding the right people to carry it out regularly:

[Our visitor research] is not as good as I'd like it to be and it's basically reliant on if I can get a volunteer or intern, as it's virtually impossible to do with the staff we've got. ... We've just had a student do an evaluation of one of our exhibitions, but I haven't seen the results from that yet.

\section{Barriers to Visitor Research}

The main barrier to undertaking visitor research at this museum is a lack of staff. There are difficulties in finding the right person who can carry out the research and can 
dedicate the necessary time to the task:

Challenges are finding the time, but the benefits [from past visitor research] have been good in terms of analysing the data and coming up with solutions for problems or issues we've been thinking about. Also, to know that you're on the right track and that you're not doing something that is completely going to not be of interest to anybody.

\section{Interview 5: Rural Gallery}

\section{Museum/Gallery Type}

This gallery is located in a small town which is part of an extended rural district. Their opening hours are Tuesday to Saturday $10 \mathrm{am}$ to $4 \mathrm{pm}$, and Sunday $1 \mathrm{pm}$ to $4 \mathrm{pm}$. The gallery is free and exhibits a lot of local and national art work. They are a registered Charitable Trust, which has the purpose of supporting, advancing and educating the local community using New Zealand art. The gallery believes their standing in the community has increased and they are hoping to become the district public gallery in the near future:

We're primarily a community gallery that started from a volunteer base, and has become increasingly professional. We show a range of material, from contemporary to cultural heritage. The programme is diverse enough that we can show both local artists and artists from elsewhere.

\section{Staff Numbers}

The gallery employs two FTE staff, plus two casual staff. They are also able to draw from a pool of more than 30 volunteers to help run the gallery's reception area. There is a goal to employ an education officer so the gallery can work with more schools and education groups:

The other thing I'd love to have in that five year plan would be an education officer and a really active schools programme. I think that would add enormously to the district, and I think there are a lot of young families that could visit more often, because they love it when they are here.

\section{Governance Structure}

As a registered Charitable Trust they are governed by a Trust Board. This Board is composed of seven trustees who are arts professionals and local Councillors, requiring a report every six to eight weeks. The main funding for the gallery comes from the Council, requiring reports twice a year which must include visitation numbers:

[We report] every six to eight weeks to our Trust Board and twice a year to the Council as the key funders who we have a partnership agreement with, 
with a structure of six service outcomes and targets, and numbers are part of that. We also use the visitors' book comments, in which we get some fantastic comments.

\section{Location}

Although the gallery is located within a town, it is focused on serving the whole district. The town itself is not often considered a destination, but the gallery would like to become a reason for people to visit the town. The gallery’s current visitation relies heavily on local, repeat visitors along with the wider arts community:

We became a Charitable Trust in 1996, and an approach was made to Council at that time to consider us the district gallery, but we've never quite made that transition. So this is what's going on at the moment, as part of us being the only existing public art museum in the area. We're not quite there yet, and obviously need the funding that goes with that.

\section{Views on Visitor Research}

The Director believes political and economic benefits of visitor research would be of particular use as the gallery is planning a major redevelopment, requiring justification and funding. However, the biggest area of interest for this gallery is in compiling data for comparative reasons, checking how they compare to other similar institutions by looking at staff, funding and visitation. A consultant has been hired to assist with gathering this comparative data. The gallery believes these comparisons can help them to not only justify their existence, but also their growth:

[Visitor research] is tied to future development plans for the gallery, so we actually need the research to be done so we can apply for increased local body funding, and also for government funding. ... We are really interested in comparative stats at the moment as part of one of our arguments to Council to increase our funding, and we've not been able to directly access that yet.

\section{Visitor Research Undertaken}

Visitation numbers and general anecdotal feedback are currently collected by the gallery by way of a visitors' book, as well as a day book for staff to log comments and conversations in. There has been a small amount of other visitor research undertaken in the past, such as face-to-face interviewing. However, work commitments of the staff meant the data were not analysed:

We've tried a couple of times just with surveys, and there was one questionnaire done with [a touring show] which was very successful in engaging visitors. But I think it worked because we had another person 
here during that show basically chasing people around with a questionnaire that was quite developed. Although they had resources to put into it, they didn't do much with it afterwards. It was an interesting exercise for us.

\section{Barriers to Visitor Research}

The Director of the gallery sees the importance in visitor research, but does not believe they currently have the resources to be able to carry it out effectively. They also believe once they have the data, advice would be required to analyse it effectively:

I've tried to get into visitor research in the past as I'm aware that we need it, but it's just difficult to find someone to allocate to it and push it, as it's just slightly lower priority. But it is going up the list. ... I'm really interested in doing it, but then the forms come in and I've already got a full-on workload, so what do I do with it once it's done?

\section{Interview 6: Medium Urban Museum}

\section{Museum/Gallery Type}

This is an urban, medium-sized museum which is open seven days a week from 10am until 5pm and charges an admission fee. There is a science focus which is dictated by the building and collection. The museum has been open for under a year since undergoing a major redevelopment. Part of the redevelopment was a change in the institution's marketing ethos, becoming more focused on international tourism:

I look at us as a visitor attraction. Part of that attraction is that we have a legacy, with a number of artefacts and stories and materials that relate to that legacy. ... We're a medium-sized museum that uses science as a hook, with the history and culture that we're also trying to get across.

\section{Staff Numbers}

The museum has 7.5 FTE staff, a pool of around 20 part-time front-of-house staff, and up to 25 volunteers.

[Our staff] are experts and are education programme focused. Each of those people is involved with different societies around the region and New Zealand, and they give back constantly. So, this place is used by them and they give back their time. Our volunteer pool comes from them when we need it.

\section{Governance Structure}

The museum is governed by a Trust Board which is a CCO, meaning the Council is the main funder and appoints the trustees. The Trust Board is made up of five trustees, with skills and experiences ranging from arts to business, and requires reports to include 
visitation numbers and satisfaction levels:

Our governance is a Trust Board, but as part of the CCO structure, we report to the Council as well. We report the number of visitors, obviously. ... There is a governing body over the Trust Board and we are a non-profit organisation.

\section{Location}

Although this museum is urban, it has location issues as it is not on a main road. They are looking at ways to address way-finding problems identified:

Another issue for us that we're very well aware of is signage ... road signage and how you get up here, as well as car parking which needs to be clearer. We have two points of entry making it more difficult.

\section{Views on Visitor Research}

When it comes to visitor research, this museum is predominantly concerned with marketing and tourism, particularly the international market. An important aspect of the visitor research which is conducted is to determine the effectiveness of their marketing, as they want to ensure their advertising is reaching as many people as possible, while delivering the right message:

If you have a limited budget, in terms of targeting your spend, you have to get maximum value for your money and identify who you want to get your message out to, and where you find them. It's important because we're here for the visitors, and if you don't know who they are and what they want, you're not hitting the mark and you're not doing what you should be doing.

\section{Visitor Research Undertaken}

Visitor research was started following the redevelopment. The museum is concerned with creating a robust benchmark against which future visitor research can be compared, as well as using it to compare with other institutions. The museum has employed a consultant to design an online survey and analyse the data. However, they are aware there are limitations to the surveying, and so combine it with other methods to add further information and build a more comprehensive picture:

[The intention was to] get a robust set of data that we can benchmark ourselves against year on year. ... We know that locals tend to fill this in rather than international visitors, which is why on top of the survey, we have also introduced a sheet for front-of-house people to pick up information when they talk to people who are visiting: where you come from, how you heard about us. So this was started as a supplement, and we also have a guest book. 


\section{Barriers to Visitor Research}

There appear to be few barriers for this museum when it comes to undertaking visitor research. As a result of limited methodological and technical expertise their main concern is around sampling and ensuring it is robust. As noted above, they are working on diminishing these concerns by combining the surveying with other visitor research methods. The surveying will continue as long as the consultant's prices do not increase significantly, suggesting possible resourcing and prioritisation issues:

I don't think it's something we can do in isolation. The guest book plays an important role. The Facebook page and Trip Advisor are there to engage the visitor in a two-way conversation which is really important, and is a part of our feedback. Obviously there's also verbal feedback, written feedback through emails, and the tick sheet and ticket sales we have going at the front-of-house as well. All of those give us a complete picture. ... Only a major price hike would mean that we'd have to stop the surveying, it currently only costs around what other surveys cost.

\section{Interview 7: Medium Urban Historic Building/Museum}

\section{Museum/Gallery Type}

This medium museum is also an urban museum, but has free entry. It is open Monday to Friday $9 \mathrm{am}$ to $5 \mathrm{pm}$, Saturday $9.30 \mathrm{am}$ to $4 \mathrm{pm}$ and Sunday 10:30am to $4 \mathrm{pm}$. The museum is defined as a historic building, which is also a working building with core business of a different nature. The visitor services staff strive to ensure the integrity of the day-today use of the building, while providing exhibition spaces and regular tours:

We define ourselves as a heritage destination and a public interest amenity that belongs to the people of New Zealand. When we advertise we always try and be linked in with history and heritage. When we categorise, that's where we prefer to be. ... There are multiple goals and we're trying to do a number of things, while not being too commercial and being guardians of the institution we represent.

\section{Staff Numbers}

This museum employs six FTE staff, eight part-time staff, and ten casual staff. They do not have volunteers. The opinions of the staff are often sought for museum developments as the Manager is aware inclusion helps staff responsibility and accountability to their jobs. An example of this was when the museum recently began visitor surveying:

It needed the team's buy-in because it did need the tour guides being comfortable saying 'tell us what you think' and phrasing it in that way. 
Through the survey development I involved the supervisors. ... I encouraged all the staff to do the survey, and made it as open as I could. And because the results have been turned around so quickly, the results were shared immediately and they've realised how useful it was.

\section{Governance Structure}

The museum is a part of the Operations Group of the building in which they reside, which in turn is part of a larger Service Group from which their funding comes. This Service Group is led by a General Manager who reports to the Director of the building. The required visitor research component of their reporting includes visitation, which is recorded by the tour guides at the beginning of each tour. Visitor satisfaction is also reported from the surveys carried out:

We report on visitor numbers with quite high level reporting. We will now report on satisfaction. Previously, we were reporting on satisfaction, but we didn't actually have measures, so we'll be able to populate that now.

\section{Location}

This museum is centrally located in a main city. It is well placed to work collaboratively with many other museums and galleries in the area and the Manager is enthusiastic about fostering these relationships:

There are a number of places at this end of town that operate museums or services under similar conditions. ... We're trying to share some ideas and some operational information that can fill a bit of a gap in terms of industry support.

\section{Views on Visitor Research}

With regard to visitor research, this institution differs from the other medium museum interviewed in its goals. Rather than focusing on marketing, the visitor research has a focus on improving high level reporting, helping to justify the institution and the funding it receives. Their visitor research is carried out regularly, with a commitment to ensuring its continued usefulness:

There are financial constraints within any organisation and we're very accountable, so the data would go through our monthly reports and annual report which helps to justify the size of the team. ... So to argue for ongoing resources you need to have a good statistical base.

\section{Visitor Research Undertaken}

The museum is very conscious of creating a robust benchmark against which future visitor research can be compared. They employed a consultant and are impressed with 
the surveys and quickly returned analysis:

We have traditionally done our own surveys which were based on quality and feedback, and we always had satisfaction rates of 90 to $100 \%$. But they were pretty small samples, and also this survey had limited usage in terms of what we were capturing, which was one of the reasons that the decision was made to try this other process which gave us much more flexibility in how we designed it.

\section{Barriers to Visitor Research}

As with the other medium museum interviewed, there appear to be no barriers to prevent this museum from carrying on with their visitor research. They are very aware of ensuring the data they collect is from a representative sample of visitors, but also that the staff understand why it is an important activity and do not feel overwhelmed by it:

My only concern is not capturing the people who don't speak English as their first language, although it's probably a small demographic for us ... [Also] making sure that we didn't overdo it so that the staff still feel it's a valuable tool and we were getting valuable information out of it.

\section{Summary}

Common themes emerging from the interviews show definite benefits of visitor research identified by the participants. These include demonstrating the institution's value, increasing funding, improving reporting and creating benchmarks. Themes also emerged regarding perceived barriers to visitor research which focused on lack of staff, lack of resources, and limited visitor research knowledge and expertise.

Gaps in visitor research understanding have been identified, which are based upon limited experience with the practice. The museums and galleries appear to know little about how to focus their visitor research, not always comprehending the full impact and utility it can have. This suggests help is needed to expand the narrow view of visitor research, leading to understanding the ways it can further benefit institutions. The next chapter discusses and analyses these issues in more detail. 


\section{Chapter Four: Common Themes}

\section{Introduction}

In this chapter my research question, which asks what the perceived needs are for visitor research and how their needs can be met, is explored through benefits and barriers identified throughout the interviews. These needs are examined within a larger context of the current visitor research practice of not only the research sample, but also of the whole population which responded to Museums Aotearoa's scoping survey. The last section of the chapter then looks at the ways in which visitor research can be expanded to be of significant use to museums undertaking it regularly, arising from a wider understanding its various uses.

\section{Current Visitor Research Practice}

Collecting visitation numbers was the visitor research practice common to all museums and galleries where interviews took place. The two medium-sized museums and one small museum also collect visitors' demographic information and satisfaction data. To supplement the visitation numbers, anecdotal feedback is regularly compiled by four of the seven museums and galleries. This feedback is mostly contributed by visitors relating their experiences to staff, making suggestions for improvements or future exhibitions and writing in visitor books. Four of the institutions stated that they carried out some surveying in the past; three of these utilised students to do so. Two of the institutions also gather data from the tours they run. Below is a table outlining each of the interviewed institutions and the visitor research they currently carry out (Table 3, page 47): 


\begin{tabular}{|l|c|c|c|c|c|}
\hline & Visitation & $\begin{array}{c}\text { Demo- } \\
\text { graphics }\end{array}$ & Satisfaction & $\begin{array}{c}\text { Anecdotal } \\
\text { Feedback }\end{array}$ & $\begin{array}{c}\text { Tour } \\
\text { Information }\end{array}$ \\
\hline $\begin{array}{l}\text { Interview 1: Urban } \\
\text { Art Gallery }\end{array}$ & $\checkmark$ & & & & \\
\hline $\begin{array}{l}\text { Interview 2: Urban } \\
\text { Heritage Building/ } \\
\text { Museum }\end{array}$ & $\checkmark$ & $\checkmark$ & $\checkmark$ & & $\checkmark$ \\
\hline $\begin{array}{l}\text { Interview 3: Urban } \\
\text { Art Gallery }\end{array}$ & $\checkmark$ & & & $\checkmark$ & \\
\hline $\begin{array}{l}\text { Interview 4: Rural } \\
\text { Museum }\end{array}$ & $\checkmark$ & & & $\checkmark$ & \\
\hline $\begin{array}{l}\text { Interview 5: } \\
\text { Rural Art Gallery }\end{array}$ & $\checkmark$ & & & $\checkmark$ & \\
\hline $\begin{array}{l}\text { Interview 6: } \\
\text { Medium Urban } \\
\text { Museum }\end{array}$ & $\checkmark$ & $\checkmark$ & $\checkmark$ & $\checkmark$ & $\checkmark$ \\
\hline $\begin{array}{l}\text { Interview 7: } \\
\text { Medium Urban } \\
\text { Historic Building/ } \\
\text { Museum }\end{array}$ & $\checkmark$ & $\checkmark$ & $\checkmark$ & & \\
\hline
\end{tabular}

Table 3: Current Visitor Research Practice

This table is relevant to my research question as it outlines the lack of varied visitor research being undertaken by the small museums interviewed. It confirms they are mostly recording visitation numbers and utilising anecdotal feedback, such as comments from visitor books. The museums doing more visitor research are: the small museum that is part of a collaborative group of museums in the area, and the two medium-sized museums with more resources.

\section{Perceived Benefits of Visitor Research}

Three related themes ran through the interviews with regard to the institutions' perceptions of the benefits of visitor research. These are practical applications and show that the museums and galleries see some validity in undertaking visitor research. The first theme is that of obtaining evidence to demonstrate the value of the institution to the management, the visitors, and the museum itself. This links to the next theme of increasing funding, which can be difficult as money is often needed to undertake the research. Finally, there are benefits in creating benchmarks which improve reporting, both to Boards and potential funders.

The museums and galleries interviewed all spoke positively about the potential benefits 
of visitor research. Statements were made such as: "I think it's a good way that you can prove yourself” (Interview 5). There is the underlying belief that visitor research demonstrates the value of a museum or gallery, being able to explore who visits, why they visit, and the perceived quality of their experience. This position was clearly articulated in an interview demonstrating how future visitor research could enhance their museum:

The benefits for us will hopefully start with finding out more about our demographic and also what they'd like to see there, what do people like or dislike about the current set-up, and then what they would like to see, or see changed, or general suggestions for a way forward (Interview 2).

Two of the museums were also specifically concerned with what their visitors learnt and how they worked that knowledge into their lives:

I'm more interested in what people actually take away with them when they leave here and if they actually apply that to other parts of their life (Interview 4).

We're now trying to change to it being a bit more of a learning experience and understanding the process, while having a tour of the buildings and its history (Interview 7).

These are specific examples of some of the purposes of museums. However, there could be exploration and further information provided by visitor research to justify these purposes. Museums can discover and cater for visitors' needs, without compromising their own visions, becoming justifiable choices over other leisure activities offered. ${ }^{2}$ Evidence can also be gathered detailing the impact the exhibitions had on their visitors and providing opportunities for adjusting exhibitions or tours which were not working as planned.

Perceived issues around visitor research appear to be better managed by the institutions with visitor research experience. Past experience can help museums to see results as practical and beneficial. This is especially the case when it comes to increasing funding: "we actually need the research to be done, so we can apply for increased local body funding, and also for government funding” (Interview 5). It appears that museums with more visitor research experience are more aware of the benefits, demonstrating that being results-oriented, focusing on a funding bid for example, can be motivating and

2 Hood, 1995, 2. 
empowering.

Some of the institutions collect anecdotal feedback from their visitors in different ways, such as in visitors' books or by noting informal conversations in day books. This feedback is generally reported as positive and constructive. However, many of the museums and galleries acknowledge that unless they carry out more rigorous and comprehensive visitor research these notions cannot be formally reported or quantified:

Intuitively and anecdotally I have a good grasp of how people are responding to things, but I don't have a formalised expression of that, which makes me grit my teeth all the time as I really want that, but haven't managed to find the time or the method or the means to do it (Interview 4).

Three of the seven museums interviewed also undertook Museums Aotearoa's scoping survey. These museums all indicated an interest in the idea of MANVS and its database, which is designed to create national benchmarks. They agreed the data would be helpful for reporting to governing bodies and for internal planning. Since the time the scoping survey was emailed out, the medium museums have employed consultants and set up visitor research processes. It was important for them to get their visitor research started and work towards creating a benchmark, reflecting a goal of Museums Aotearoa's proposed database.

\section{Barriers to Visitor Research}

As previously mentioned, there are similar reasons given by institutions as to why they do not, or cannot, undertake visitor research. Despite the range in institutional type, number of staff, resourcing, and governance structures, many of the small museums and galleries identified the same challenges and obstacles to conducting more comprehensive visitor research. Issues around lack of staff and other resources, especially money, appear to dominate. Institutions also acknowledged some shortcomings with regard to experience and their ability to convey the importance of visitor research to their staff and management. The medium-sized museums conduct a greater range of visitor research, suggesting that size (budget and staff) has a positive impact on whether research is conducted. These issues are discussed in more detail below.

\section{Lack of Staff}


Due to the small size of the museums and galleries, staff (and volunteers) are often required to undertake a range of tasks and the demand on their time is high. Various interviewees mentioned the heavy workload already placed upon their institution's limited number of staff:

I've managed to get a little bit better staffing and have managed to get a bit more support, but even so it's a nightmare trying to manage and juggle everything (Interview 1).

There are many operational demands which make it difficult for these small museums to consider undertaking visitor research. It is also believed that there is not only a lack of time to carry out the visitor research, but there is also little time for analysing the data:

Another body [is necessary], somebody who could devote their time to doing [visitor research] ... You might find a day where you can interview people, but then it's three months later before you've got some time to do that again and you've lost all of your momentum (Interview 4).

\section{Lack of Resources}

Most of the small museums have limited budgets which are tightly controlled. The money available is often committed to operational purposes with little, if any, flexibility. Throughout the interviews, respondents detailed the frustration this lack of resources causes:

That's probably the biggest issue actually, having the time and resources to do them and then analyse them, and then evaluate them to see what we can do with the results (Interview 2).

These budget restrictions make it difficult to justify allocating money to pay for dedicated visitor research positions or hire consultants.

\section{Lack of Visitor Research Knowledge/Expertise}

During the interviews, some of the respondents mentioned their concern regarding a lack of knowledge and expertise in visitor research. Some institutions reported that they had been able to collect data, but had not known how to analyse it:

I'm really interested in doing it, but then the forms come in and I've already got a full-on work load, so what do I do with it once it's done? I would need advice on how best to extract the information that I wanted to. The intent is definitely there (Interview 5).

Others said that they did not have the skills or knowledge to design visitor research or identify what data was important for them to gather: 
I would probably go to a colleague who has a lot of experience in this area [of visitor research] and ask him, as I wouldn't even know where to begin (Interview 1).

Others stated that it would be useful to have external professional support of a practical nature to assist them with visitor research:

It would be useful if National Services could grow their national development officers to have one person devoted to helping museums with visitor research, or somebody who could go in and do some of that research for them, working with people to set it up and make it easy (Interview 4).

It could also be suggested that some of the museums and galleries may not have grasped the full concept of visitor research and what it can encompass. Therefore, it might be useful to increase awareness around the transformative impact that visitor research can have on an organisation, allowing them to advocate for its use where appropriate.

\section{Expanding the Understanding of Visitor Research}

While perceived benefits and barriers were identified throughout the interviews, there are other areas that require further understanding to enhance and diversify visitor research practices. A lot of emphasis is currently placed on the collection of visitation numbers, with less consideration for what else is encompassed by visitor research. Due to the acknowledged lack of resources and expertise, this narrow view suggests that there are difficulties for small museums and galleries in knowing how to focus other types of visitor research, what other visitor research they can do, what research can tell them, or how data can be used.

\section{Narrow View of Visitor Research}

For an institution to have a clear understanding of the value of visitor research, it helps for management to also know this value. Otherwise it is difficult for the institution to allocate resources to prioritise visitor research. Visitor research can also be difficult if there are staff who do not see the value, as employees' understanding and co-operation is also vital. It helps when all staff are involved in data collection within small museums, so that they can have an understanding of, and commitment to, the process.

Of the six institutions interviewed with Strategic Plans all must report their visitation numbers. Two must also report general feedback or satisfaction. Regarding visitation, 
the interviews captured statements such as:

I wouldn't want visitation to be a big thing, but my Board definitely wants those numbers counted and wants to know them (Interview 1).

We report on visitor numbers and customer satisfaction (Interview 2).

Visitor numbers are required in the reporting (Interview 3).

We currently just have visitor numbers, which have been collated into graphs and we use them in presentations to Council primarily (Interview 5).

We report the number of visitors, obviously (Interview 6).

We report on visitor numbers with quite high level reporting (Interview 7).

These responses suggest an importance placed upon visitation numbers by governing bodies, which are often reported in isolation from other visitor research. Although visitation is one way to measure the success of a museum or gallery, additional information could augment these numbers, including repeat visitation data, visitor profile data, and learning and engagement data. These data can be gathered using methods such as (but not limited to) face-to-face surveying, observations, focus groups, or in-depth interviewing. As suggested in the literature review in Chapter One, data collected using methods such as these may be more resource-intensive, but can provide comprehensive information about the profile of visitors, the type of experience visitors have, and the success of exhibitions. ${ }^{3}$

There is also a need for a better understanding of visitation numbers, for example in identifying repeat visitation. The lack of knowledge and understanding around the wider context of visitor research possibly explains the reliance on straightforward practices, such as collecting visitation numbers. Increased awareness, so that museums can carry out other types of visitor research regularly, consistently and rigorously, using a strategy to guide the information collected, would place reporting within a detailed context which clearly represents the institution. By encouraging these other forms of visitor research, the issue of their resource-intensive nature cannot be ignored. This is addressed in Chapter Five where recommendations are made for helping meet the needs of small museums with regard to visitor research in general.

3 Hooper-Greenhill, 2006, 368. 
Resources aside, exploration of different types of visitor research can also depend upon an institution's philosophy and how they prioritise the activities for which they are responsible:

I guess our priorities have been elsewhere, it's not just 'we haven't got any money, but it's something we should do' ... But also it's not a priority because we're not driven by numbers (Interview 1 ).

This suggests that when visitor research is considered, there is a reliance on an institution's mission and their perceived relationship with their visitors. In the case of Interview 1, as the organisation in question does not have to justify their existence in terms of visitation targets or conventional visitor satisfaction, they are able to focus on building their reputation in the national and international art community. Therefore, it can be difficult for institutions such as this to see how visitor research might be of use and they may not perceive the benefits. However, visitor research could still be done to assess how effective they are in reaching their target audience and the extent of their reach. Earlier quotations from this interview also talked about community buy-in, showing that they want to be liked by their community. This reinforces the idea of visitor research coming down to priorities and the museum's philosophy.

Therefore, museums and galleries must first understand the extent to which visitor research can impact upon their institution before they can change their mission or philosophy to be more explicit about their visitor research requirements. However, if presented with a proposal which laid out what to do, how to do it and of what use it would be, they might be more willing to consider visitor research and its implications. Highlighted in the literature review was the concept that regularly gathered information can help a museum prove its long term value to stakeholders. ${ }^{4}$ The results can range from finding out the target audience is not being reached, to validation of an exhibition's success, to uncovering issues around way-finding. Understanding visitor research allows it to be justified as a purposeful activity, with appropriate resources being allocated.

\section{Ways to Focus Visitor Research}

It is valuable to know how many people visit an institution, but it also helps to find out who visits (and does not visit), why they visit and what they are interested in: whether

4 Scott, 2009, 203-204. 
they liked the exhibitions (and why/why not), and what they learned. This can be an overwhelming prospect for some institutions who have limited staff. There is such variation in what people are interested in that if the information is collected, museums and galleries may feel obliged to act upon all suggestions, increasing heavy workloads even further. ${ }^{5}$ However, it is possible to appreciate and consider all suggestions, while maintaining the institution's integrity by acting upon any suggestions sympathetic to their vision. This was expressed by one gallery regarding the possibility of future research:

We wouldn't necessarily give them what they wanted, but we'd do it in a way that perhaps offered opportunities for people to engage in the subject they like, in a way that we were keen to provide (Interview 1).

One way for museums to start looking at visitor research could be by examining what they are already concerned with, then exploring ways to validate or improve these areas.

Overall, there are similar goals when it comes to the quality of visitor experiences, although the history museums and the art galleries interviewed appeared to view these experiences differently. Firstly, the history museums want their visitors to have an enjoyable experience, as one result can be increased visitation through repeat visits and word-of-mouth recommendations. Some theories suggest that a way for museums to reinforce their accountability can be by aiming to build a broader audience. ${ }^{6}$ Two of the museums articulated this position clearly:

You want people to have that great experience, to go away and tell other people about it and then they come as well. It then extends from there as they tell other people too (Interview 2).

If we don't deliver a satisfactory visitor experience, we don't get the benefit of word-of-mouth. And word-of-mouth is our strongest advertising tool (Interview 6).

These museums believe the quality experiences they provide can increase visitation numbers. Yet, it can be argued that without undertaking visitor research asking visitors why they visited and how they heard about the museum, there is no way to confirm whether or not this is the case.

Similarly, the art galleries are looking to create quality experiences for their visitors. However, the galleries interviewed did not want to limit their focus on visitation, being

McLean, 1999, 87.

6 Kotler, 1999, 5. 
only one part of measuring the services and experiences provided. One gallery stated:

The thing about visitor numbers is that you have to put that against quality of experience, you don't just want people coming through the door (Interview 5).

Another gallery similarly said:

What kind of experience are they having, and how do we actually determine the quality of that experience, and what have they learnt from it? It's not just about numbers (Interview 1).

These galleries appear to want a more holistic approach to assessing success and appear concerned about the limited focus on visitation. However, as they are not undertaking any research to ensure the visitors' experiences are of the quality they plan for, it can be difficult to argue they are successfully providing the experiences they are striving for.

\section{Impact and Utility of Visitor Research}

For museums and galleries that are publicly funded there is an expectation to meet their communities' needs in diverse ways, ensuring relevance and accountability. Adapting easily to work with the needs of a community appears to be one of the benefits of being a small institution with less bureaucracy. ${ }^{7}$ The literature explored earlier in Chapter One suggests that these are institutions where decisions can be made quickly. This can lead to prompt actions, taking suggestions into account and delivering high-level services. ${ }^{8}$ However, finding appropriate methods to uncover visitors' needs is where work needs to be done, exploring ways visitor research can help to provide this information.

During an interview one of the medium-sized museums pointed out:

We've got a method that is effective for us [i.e. online surveying], with regard to resources and time, to find out more about our visitors (Interview $6)$.

This statement reiterates the importance of accepting that there is no single method of visitor research which will work for all museums and galleries. Each museum is unique and located within communities with different requirements and demands. ${ }^{9}$ Therefore, each institution needs to explore visitor research to pinpoint appropriate, achievable and manageable methods to fulfil their needs, while working with their available resources.

\footnotetext{
McNichol, 2005, 241.

McNichol, 2005, 241.

McNichol, 2005, 246.
} 
Museums and galleries can be said to be cultural information providers, quality institutions which have unique attributes, including the “'intrinsic' value of museums as gathering places”. ${ }^{10}$ The rural institutions interviewed, more so than urban ones, appear to be increasing as civic spaces, being used for a broader range of services for their whole communities, places people can go to socialise or ask for advice:

Our secondary function is as a community art centre. We act as that because that's how people treat us, whether we like it or not. They come in and they expect us to be a source of information (Interview 5).

Social events are also becoming more frequent, providing a different environment for functions: "We've also had farewells here and a few cocktail parties. So it's becoming more of a social and civic space” (Interview 4). Although this statement has a commercial element to it, it also suggests, along with the previous quote, that due to fewer alternatives within some rural societies, the museums and galleries are offering different services, leading to more accessible and interesting civic spaces. It is this ability to combine formal and informal experiences which is said to be a valuable tool for museums, encouraging visitors to believe that they are prudently using their limited leisure time. ${ }^{11}$ Utilising visitor research could help these museums further explore what other services, if any, their communities want from them.

In contrast, the urban institutions generally targeted their programmes towards fulfilling the needs of special interest groups. This narrower focus could partly be due to their specific collections and interests and partly due to the wider range of facilities and services available around them. These groups have interests relevant or sympathetic to the museums' directions:

There are quite close connections with local historical societies and those need to be fostered, but there are others that could probably be a bit more involved (Interview 2).

There are also specific audiences targeted for exhibitions as well as public programmes:

We're actively promoting public programmes along with every exhibition, and I think we've had some quite marked success in targeting different audiences for different projects. We will look at every exhibition and decide who its audience is ... And in each instance we'll try and reach out to those people to let them know it's on (Interview 1).

The specific community groups being catered for create an important opportunity for

10 McNichol, 2005, 243.

11 Kotler, 2001, 419. 
visitor research. Some of the literature reviewed emphasised the need for museums to recognise and respond to the agendas of these specific groups, then to use the information to create more successful museum experiences. ${ }^{12}$ How effectively are these groups being reached and how satisfied are they with their experiences? If able to be prioritised, there are different types of visitor research which could help discover a museum's success in meeting its aims. This visitor research would encompass both successes and failures, helping improve exhibitions and consequently visitors' experiences. As discussed earlier, some theorists state the importance of different types of visitor research being utilised, as knowledge of visitor experiences as well as demographics is vital for efficient management and growth. ${ }^{13}$

Although they have many special interest groups to work with, two of the urban museums also explained how they are beginning to look towards providing broader services for their communities. These museums are hoping to become more practical and inspirational on wider levels, embracing collaborative networks; this illustrates the important concept surrounding willingness to co-operate and share information: ${ }^{14}$

I'd certainly collaborate with other community groups, garden groups, historical groups, artists ... we're going to look at all sorts of different options based around collaborating with other groups and people hopefully (Interview 2).

This shows an emerging awareness of the social well-being of a community as a whole, and the part museums and galleries must play in nurturing this well-being. Visitor research could make it possible for small museums to discover other less obvious groups in their communities and exhibit on topics of interest. It is argued that this type of research provides social and intellectual stimulation by exploring the make-up of the community, their interests, needs, and opinions on the role of the museum or gallery: ${ }^{15}$

Part of this sub-brand we've just developed is about inspiring our community, which frames everything up but is still quite new. That's about giving back to our local community and saying 'you mean something to us and we want to give back to you' (Interview 6).

The ability to know the community well, and work closely with them, are some benefits small and medium-sized museums have over large museums, as they serve smaller

2 Falk and Dierking, 1992, 37.

13 Hooper-Greenhill, 2006, 368.

14 McNichol, 2005, 242.

15 Neal, 1987, 5. 
populations. Therefore, it could be said these museums and galleries are moving towards providing more social experiences which can be enjoyed in many different situations. ${ }^{16}$ Once the barriers listed above can be overcome, there could be room for visitor research to be utilised to enhance the knowledge museums have regarding their communities, allowing them to become more personalised, welcoming and inclusive.

\section{Summary}

All of the interviewees acknowledged that there could be some use in visitor research; some articulated this idea pragmatically: “everybody knows it’s a good thing to do, but it's just a case of how can you do it" (Interview 4); and some hesitantly: "I presume there are advantages and there are lots of people who would tell you so" (Interview 1). But if museums and galleries are not aware of the full range and benefits of visitor research, they are less likely to see its value as a regular activity.

Experience can lead to a change in attitude, especially with regard to whether museums and galleries felt that problems outweighed the perceived value. One small gallery stated:

The main issues in small museums and galleries not undertaking visitor research are the usual reasons: lack of staff, lack of time, lack of money. The three go together. Unless we can find a smarter way of doing it, it's always going to be an issue (Interview 5).

Whereas, another small museum announced:

The benefits will outweigh the challenges, because we really need to find this information out ... to find out what the problems are, what people want to see or do more, and work towards achieving that (Interview 2).

Therefore, perhaps the "smarter way" mentioned by Interview 5 could begin with a change in philosophy, namely a philosophy that acknowledges the difficulties that will be faced, but does not let the challenges dissuade them from carrying out visitor research. The next chapter is the last, summarising the conclusions I have reached carrying out this research. Also included for consideration are sections outlining potential implications for support and guidance, as well as possible recommendations for further study.

16 Kotler, 2001, 419. 


\section{Chapter Five: Conclusions}

This research has set out to fill a distinct gap with regard to identifying the visitor research needs that small museums have, and ways in which these needs might be met. Reflecting on the theories discussed in the literature review, there appears to be a need to explore ways to help small museums understand visitor research and the variety of uses it has. This conclusion was reached by firstly examining what small museums are currently achieving, and secondly by discussing what they would like to achieve. A result of this investigation was the indication that some small museums need help to explore a broader range of visitor research and understand the ways in which it can help them achieve their goals.

My conclusions acknowledge that all respondents saw some value and use in visitor research. On top of this, some of the museums are already in a position to undertake more varied visitor research. However, a lot of the visitor research has a narrow focus, predominantly based upon visitation numbers. These institutions are concerned with creating quality experiences for their visitors, but heavily rely upon one method (visitation numbers) to gauge the level of success. The main barriers preventing broader visitor research are lack of resources and limited expertise.

I also suggest that visitor research is not widely perceived by small museums as a method which is able to improve visitors' experiences. There are few requirements by governing bodies to undertake visitor research for reporting purposes (other than visitation numbers and in some instances satisfaction levels) often leading to visitor research not being prioritised. These museums are in a difficult position, needing money to undertake visitor research, while often recognising that the research might help them argue their cases to receive more funding. An implication here is if more visitor research was required to be reported upon, especially if funding was allocated, it might be made a priority. The governing bodies and the institutions have to both agree that without visitor research it can be difficult to develop in ways that interest visitors and grab the attention of the community.

A way to help address these difficulties is for potential uses of visitor research to be explored, justifying the activity and ensuring its value. It is worth remembering Scott's 
argument that it is this concept of 'value' which is becoming the "overarching framework with which to articulate, advocate and substantiate the importance of museums in the $21^{\text {st }}$ Century”. ${ }^{1}$ These issues are discussed in more detail below.

\section{Implications for Support and Guidance}

The findings of this study have suggested a number of implications for the future practice of visitor research within small museums and galleries. The interviews identified three specific needs which have to be addressed in order for small institutions to carry out regular visitor research. Firstly, the need for education about visitor research, focusing on aspects such as: why it is important, how it can influence and inform a museum/gallery, how it can be carried out, where to seek advice. Some institutions need to be shown the usefulness of the collected data (such as Interview 1) whereas others already see its value but need help with implementation (such as Interviews 4 and 5). Secondly, there is a need for an availability of practical knowledge and access to expert assistance to design, implement, analyse and report visitor research. Finally is the requirement for funds being available to ensure the research and analysis are undertaken professionally, regularly and efficiently. Regardless of the understanding that a small museum may have of visitor research, both external support and accessibility of funding have to be available if they are to be expected to undertake robust visitor research of a high quality.

The suggestion of education has an implication for the large museums with dedicated visitor research funding and resources (such as the Museum of New Zealand Te Papa Tongarewa and the Auckland War Memorial Museum) and support organisations such as Museums Aotearoa and National Services Te Paerangi. There are people within these institutions, and the wider museums and cultural sector, who are able to provide advice, support and direction. MANVS is a starting point, helping meet some of the needs of small museums. Museums participating in this project are provided with surveys, instructions for implementation, as well as basic analysis of their data. However, in order to ensure participation, there needs to be "buy-in” from the museums. This is also limited as the survey is restricted to Museums Aotearoa members.

A practical recommendation for access to knowledge and assistance would be for a

1 Scott, 2009, 195. 
shared list of contacts for people and organisations that have visitor research expertise and are willing to participate in knowledge sharing. Establishing networks, such as online forums, workshops and support groups would be a valuable step in creating an opportunity to share knowledge and ideas. It would be useful for National Services Te Paerangi to expand their online visitor research guides to directly address the issues of small museums. They do offer visitor research guides which acknowledge the costs associated with undertaking visitor research, but there are no suggestions to help mitigate these costs. As suggested in Interview 4, it would also be a helpful service if experts were available who could regularly visit museums for practical assistance. These would be museums that want to be shown how to undertake visitor research, while also learning about the ways the data can be used.

Availability of funding is a less straightforward issue as it relies on money being allocated by someone for the specific purpose of visitor research. However, this could be achieved if a fund were to become available from a funding body such as the Ministry for Culture and Heritage, which could be applied for, and used to target visitor research within small museums. One way that funding could be offered is through “start-up” grants, allowing museums to undertake the initial visitor research. The gathered data would then allow them to demonstrate the need for subsequent funding from current or new funders.

\section{Recommendations for Further Study}

As discussed earlier, one limitation of this research is that it only looks at a small sample of small museums and galleries. Thus, questions have arisen which are in need of further investigation, for example, whether there would be similar results if the research were to be undertaken as a national study involving a more representative sample. Nationally representative research would allow the findings to be generalised and sound resources developed which could further assist visitor research practice.

More broadly, studies are also needed to establish whether the issues preventing visitor research are unique to small museums, or whether they also affect museums of other sizes, or alternatively whether there are different barriers. Micro museums with no paid staff, as well as a larger sample of medium-sized museums which have more access to resources, should also be explored. 
A further study could also assess how visitor research support would be best distributed to small museums. For example, whether it would be realistic for support to come in the form of experts visiting the museums with a specific focus on visitor research, or whether detailed online workshops or other publications would be more practical to implement.

Previously, there has been little done to publicise visitor research as a valuable activity at a national level, especially among small museums where fewer museum professionals are employed. If there has been no visitor research practice or experience within an institution, it is difficult for them to recognise what visitor research entails and what it can help to achieve. In response to this, Museums Aotearoa and VUW have now begun MANVS, a project to establish a national framework with the goal of standardising visitor profile research across New Zealand's museums and galleries. Perhaps this might be the catalyst which brings visitor research to the fore within the museum and gallery community, creating discussion, and potentially a change in the culture surrounding visitor research within New Zealand. 


\section{Bibliography}

Adams, Roxana, ed. Museum Visitor Services Manual. Washington, D.C: American Association of Museums, 2001.

Black, Graham. The Engaging Museum: Developing Museums for Visitor Involvement. London: Routledge, 2005.

Creswell, John W. Research Design: Qualitative, Quantitative, and Mixed Methods approaches. Thousand Oaks, California: Sage Publications, 2009.

Doering, Zahava D. "Strangers, Guests, or Clients? Visitor Experiences in Museums." In Museum Management and Marketing, edited by Richard Sandell and Robert R. Janes, 331-344. Milton Park, Abingdon, Oxon; New York: Routledge, 2007.

Falk, John H, and Lynn D Dierking. The Museum Experience. Washington, D.C: Whalesback Books, 1992.

Gilbert, G. Nigel, ed. Researching Social Life. 3rd ed. Los Angeles: SAGE, 2008.

Harrison Kubany, Elizabeth, and Suzanne Stephens. "The Anti-Bilbao.” Architectural Record 188 (2000): 113-115.

Hood, Marilyn G. “Audience Research Tells Us Why Visitors Come to Museums - and Why They Don't Come.” Paper presented at Evaluation and Visitor Research in Museums Towards 2000, Powerhouse Museum, Sydney, Australia, March 1995.

Hood, Marilyn G. “Staying Away: Why People Choose Not to Visit Museums.” In Reinventing the Museum: Historical and Contemporary Perspectives on the Paradigm Shift, edited by Gail Anderson, 150-157. Walnut Creek, California: AltaMira Press, 2004.

Hooper-Greenhill, Eilean. “Studying Visitors.” In A Companion to Museum Studies, edited by Sharon Macdonald. Blackwell Companions in Cultural Studies 12, 362-376. Malden, MA: Blackwell Pub, 2006.

Kotler, Neil. “Delivering Experience: Marketing the Museum’s Full Range of Assets.” Museum News (May/June 1999). Accessed May 22, 2010. http://www.aamus.org/pubs/mn/MN_MJ99_DeliveringExperience.cfm? 
Kotler, Neil. "New Ways of Experiencing Culture: the Role of Museums and Marketing Implications.” Museum Management and Curatorship 19 (2001): 417-425.

Kotler, Neil G, and Philip Kotler. Museum Marketing and Strategy: Designing Missions, Building Audiences, Generating Revenue and Resources. 2nd ed. San Francisco, CA: Jossey-Bass, 2008.

Kvale, Steinar. Interviews: An Introduction to Qualitative Research Interviewing. Thousand Oaks, California: SAGE, 1996.

Lynch, Rob, Christine Burton, Carol Scott, Peter Wilson, and Philip Smith. Leisure and Change: Implications for Museums in the 21st Century. Sydney: University of Technology Sydney; Powerhouse Museum, 2000.

Mason, Jennifer. Qualitative Researching. 2nd ed. London: SAGE, 2002.

McCarthy, Conal, and Bronwyn Labrum. "Museum Studies and Museums: Bringing Together Theory and Practice.” Te Ara 30 (2005): 4-11.

McLean, Kathleen. “Museum Exhibitions and the Dynamics of Dialogue.” Daedalus 128 (1999): 83-107.

McNichol, Theresa. “Creative Marketing Strategies in Small Museums: Up Close and Innovative.” International Journal of Nonprofit and Voluntary Sector Marketing 10 (2005): 239-247.

Museums Aotearoa. Museums Aotearoa: About Us. Accessed March 11, 2011. http://www.museums-aotearoa.org.nz/Site/about/default.aspx.

Museums Aotearoa. A Strategy for the Museum Sector in New Zealand. Wellington, New Zealand: Museums Aotearoa, 2005.

Neal, Arminta. Help for the Small Museum: Handbook of Exhibit Ideas and Methods. Boulder, Colorado: Pruett Publishing Company, 1987.

Parman, Alice, and Jeffrey Jane Flowers. Exhibit Makeovers: A Do-It-Yourself Workbook for Small Museums. Plymouth, United Kingdom: AltaMira Press, 2008. 
Piper, Heather, and Helen Simons. “Ethical Responsibility in Social Research.” In Research Methods in the Social Sciences, edited by Bridget Somekh and Cathy Lewin, 56-64. London: SAGE, 2005.

Punch, Keith. Introduction to Social Research: Quantitative and Qualitative Approaches. 2nd ed. London: SAGE, 2005.

Reibel, Daniel B. Registration Methods for the Small Museum. 3rd ed. Walnut Creek, California: AltaMira Press, 1997.

Rowe, Paul, and Wallis Barnicoat. "NZMuseums: Showcasing the Collections of All New Zealand Museums.” In Museums and the Web 2009: Proceedings, edited by J Trant and D Bearman. Paper presented at presented at the Archives \& Museums Informatics, Toronto, 2009. Accessed May 23, 2010. http://www.archimuse.com/mw2009/papers/rowe/rowe.html.

Rubin, Herbert J., and Irene Rubin. Qualitative Interviewing: The Art of Hearing Data. Thousand Oaks, California: SAGE, 2005.

Sarantakos, Sotirios. Social Research. 3rd ed. Basingstoke, Hampshire: Palgrave Macmillan, 2005.

Scott, Carol A. "Exploring the evidence base for museum value.” Museum Management and Curatorship 24 (2009): 195-212.

Silverman, Lois H. “Visitor Meaning-Making in Museums for a New Age.” Visitor Studies 4 (1992): 156-161.

Spinazze, Angela T. “Technology's No Tea Party for Small Museums.” In The Digital Museum: A Think Guide, edited by Herminia Din and Phyllis Hecht, 121-134. Washington, DC: American Association of Museums, 2007.

Te Papa National Services Te Paerangi. “Introduction to Visitor Surveys.” Resource Guides Customer Service (June 2001). Accessed December 15, 2010. http://www.tepapa.govt.nz/sitecollectiondocuments/tepapa/nationalservices/pdfs/ resourceguides/customerservice/visitors\%20survey.pdf. 
Te Papa National Services Te Paerangi. “Know Your Visitors.” Resource Guides Customer Service (June 2001). Accessed December 15, 2010.

http://www.tepapa.govt.nz/sitecollectiondocuments/tepapa/nationalservices/pdfs/ resourceguides/customerservice/visitors.pdf.

Whitehead, Chris. "Visiting with Suspicion: Recent Perspectives on Art and Art Museums.” In Heritage, Museums and Galleries: An Introductory Reader, edited by Gerard Corsane, 89-101. London: Routledge, 2005.

Wilkinson, T.M. “The Core Ideas of Research Ethics.” In Research Ethics in Aotearoa New Zealand: Concepts, Practice, Critique, edited by Martin Tolich, 13-24. Auckland, New Zealand: Longman, 2001. 


\section{Appendix A - Interview Guide}

\section{Community Value and Involvement in the Museum}

1. What type of museum are you?

How would you describe your museum?

Do you have a secondary function or a special purpose or theme?

2. What makes this museum a unique attraction for local visitors?

3. What do you know about your visitors?

(e.g. characteristics/demographics: what they like/dislike).

a. How did you find this out?

4. Are there any groups in your community that you would like to see visiting more regularly?

Why might they be important to your museum?

5. Are there any specific ways your museum works with the local community?

6. Are there other ways you want to involve the community in your museum?

7. Would you consider collaborating with other groups or museums in the area for knowledge sharing and/or promotional purposes?

\section{Current and Ideal Practice}

8. Does your museum carry out visitor research? [Next section if yes:]

\section{If no:}

9. What factors have prevented or discouraged you from doing visitor research?

10 . Would you consider doing visitor research in future?

(If yes) Why - what would be the advantages?

(If no) Why not - what would prevent you from undertaking research?

11. Is there anything that might encourage you to undertake visitor research

e.g. specific project: external assistance: financial support?

If yes:

12. Why did you decide to do visitor research?

13. Which research methods has your museum used and what data have you collected?

a. How often have you been able to do this research?

14. Who did you employ to conduct your visitor research and how long was it run for?

15. How did you find the research process you used?

a. What were the challenges and benefits of doing the research?

b. What impact did the research have and how was it used?

16. Would you undertake visitor research again?

(If yes) Why - what would be the advantages?

(If no) Why not - what would prevent you from undertaking research?

17. Is there anything that might encourage you to undertake further visitor research e.g. a specific project: external assistance, financial support? 
18. What problems have you faced in carrying out visitor research?

19. Are there any other problems might you face in planning future visitor research?

20. What information would it be valuable for you to collect and what would you use it for?

\section{Funding and Management}

21. Are you required to report to your governing body?
a. If so, what are you required to report on?
b. Where/how do you collect the information?
c. Does this require visitor research?

22. Are there other visitor research experienced people available to give the museum assistance in its operation, and with any funding and resource issues?

a. Who/what role do they have? What kind of support have they provided or offered to provide?

23. How often do you update or change your exhibitions and displays?

a. How do you decide what to focus on?

b. Have you used visitor research to inform the development of exhibitions, and assess the success of exhibitions?

24. What are the goals for the museum over the next five years?

a. Are there any plans to help achieve these goals?

b. How will you know whether you've been successful in achieving the goals?

c. What data are you collecting to monitor your success?

25. What do you think would be the ideal way for your museum to be promoted?

a. Is this something you can achieve, and if not what is stopping you? 


\section{Appendix B - Ethics Approval}

TE WHARE WĀNANGA O TE ŪPOKO O TE IKA A MĀUI

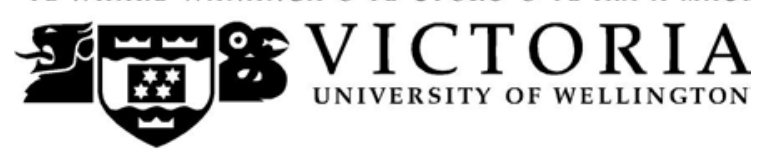

MEMORANDUM

Phone 0-4-463 5676

Fax 0-4-4635209

Email Allison.kirkman@uw.ac.nz

\begin{tabular}{l|l}
\hline TO & Casimar Larkin \\
\hline COPY TO & Lee Davidson \\
\hline FROM & Dr Allison Kirkman, Convener, Human Ethics Committee \\
\hline
\end{tabular}

\begin{tabular}{l|l}
\hline DATE & 26 October 2010 \\
\hline PAGES & 1 \\
\hline SUBJECT & $\begin{array}{l}\text { Ethics Approval: No 18025 Small Museums' Participation on } \\
\text { Visitor Research }\end{array}$ \\
\hline
\end{tabular}

Thank you for your applications for ethical approval, which have now been considered by the Standing Committee of the Human Ethics Committee.

Your applications have been approved from the above date and this approval continues until 31 March 2011. If your data collection is not completed by this date you should apply to the Human Ethics Committee for an extension to this approval.

Best wishes with the research.

Allison Kirkman

Convener 


\section{Appendix C - Consent Form}

\section{CONSENT TO PARTICIPATION IN RESEARCH}

\section{Title of project:}

\section{Small Museums' Participation in Visitor Research}

I have been given and have understood an explanation of this research project. I have had an opportunity to ask questions and have them answered to my satisfaction. I understand that I may withdraw myself (or any information I have provided) from this project before the $30^{\text {th }}$ of November 2010 without having to give reasons.

I understand that any information I provide will be kept confidential to the researcher and the supervisor, the published results will not use my name, and that no opinions will be attributed to me in any way that will identify me, and that I will have an opportunity to check the transcripts of the interview before publication.

I understand that the tape recording of interviews will be electronically wiped at the end of the project and the data I provide will not be used for any other purpose or released to others without my written consent.

I would like to receive a summary of the results of this research when it is completed. Yes/No

If Yes, please provide email address:

I agree to take part in this research Yes/No

Name of participant (please print clearly):

Signed:

Date: 


\section{Appendix D - Interview Invitation}

\section{Small Museums’ Participation in Visitor Research}

Researcher: Casimar Larkin, Museum \& Heritage Studies Programme, Victoria University of Wellington

Hello,

I am a Masters student in the Museum and Heritage Studies Department at Victoria University of Wellington. As part of this degree I am conducting research as part of the requirements of my dissertation, and I would like to invite you to participate.

I am undertaking a dissertation which is set within the field of visitor research within museums and galleries, looking in particular at small and micro museums. This research is further located within a larger visitor research project which is being undertaken by Museums Aotearoa. You have been invited as you are a member of a small museum, and if you decide to participate, you will be asked to meet with me for an interview about your experiences and opinions of visitor research within your museum.

In particular, we will discuss your ideas surrounding current and ideal practice for visitor research in your museum, funding and management, and community value and involvement. The meeting will take place at your museum if appropriate, at a mutually agreed upon time, and should last between one and two hours. With your permission, the interview will be recorded so that I can accurately reflect upon what has been discussed. I will transcribe and edit the sections of the recording which are relevant to my research and will then send them through to you for checking.

Participation is confidential. Study information will be kept in a secure location. The results of the research will be discussed in my dissertation, but your identity will not be revealed. Taking part in the research is your decision. You do not have to be in this research if you do not want to. Should you feel the need to withdraw from the project, you may do so without question at any time before the $30^{\text {th }}$ of November 2010 . You may also decide not to answer any question you are not comfortable with. The Victoria University of Wellington Human Ethics Committee has granted approval for this project.

The information you provide will be included in my dissertation on a confidential basis. Any direct quotations used will be attributed to a pseudonym. No other person besides my supervisor, Dr Lee Davidson, and I will have access to the data. Recordings and transcripts will be destroyed once the dissertation has been marked.

The dissertation will be submitted for marking to the Museum and Heritage Studies Programme and will be deposited in the University Library. I will be happy to answer any questions you have about the study. You may contact me at larkincasi@myvuw.ac.nz, or my research supervisor, Lee Davidson, lee.davidson@vuw.ac.nz if you have course related questions or problems. 
Thank you for your consideration. I will call you within the next week to see whether you are able to participate.

Kind regards,

Casimar Larkin

larkincasi@myvuw.ac.nz

Lee Davidson

Senior Lecturer

Museum \& Heritage Studies

044635929

lee.davidson@vuw.ac.nz 